\title{
الذّكاء العاطفي وعلاقته بالقيادة الخادمة لدى قائدات الملدارس في محافظة المذنب من وجهة نظر المعلّمات
}

\author{
علي صالح الشايع \\ أستاذ الإدارة التربوية- كلية التربية- جامعة القصيم التيايم \\ ashyea@gmail.com \\ عواطف بطاح المطيري \\ ماجستير إدارة تربوية- كلية التربية- جامعة القصيم
}

Mesh1434@windowslive.com

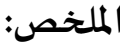

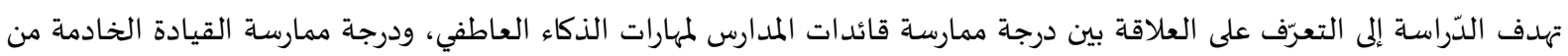

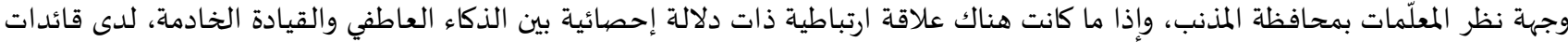

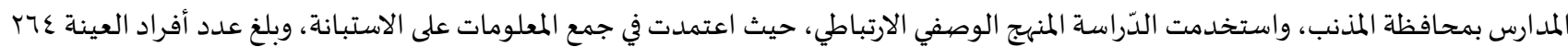

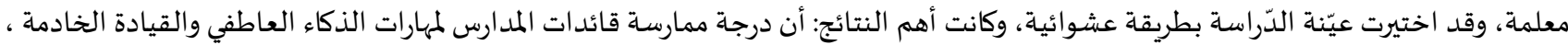

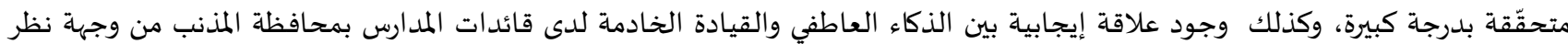

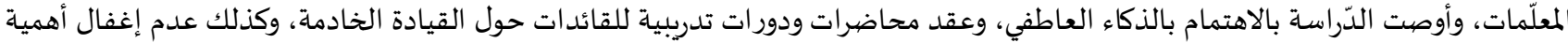
العلاقات الإنسانيّة وتحسينها بين القائدات والمعلّمات.

الكلمات المفتاحية: الذكاء العاطفي، القيادة الخادمة، محافظة المذنب.

\section{(ब) (1)}

المقدمة:

تقوم القيادة الإداريَّة- في ظلِّ التطورات المتسارعة في شتى الميادين- بدور مهٍِّ وجوهري في تطوير العمل وتجويده، فالمدرسة باعتبارها

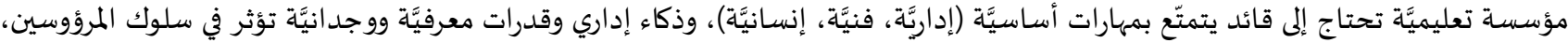

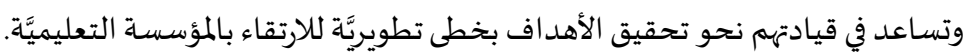

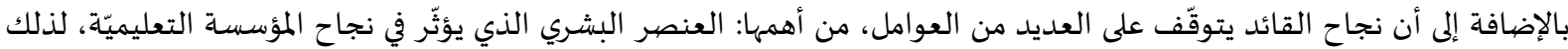

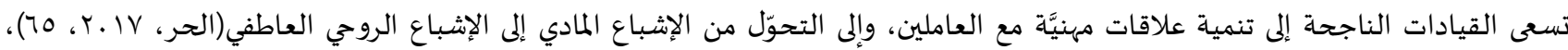

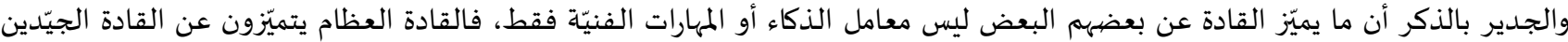

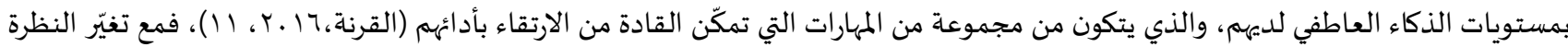

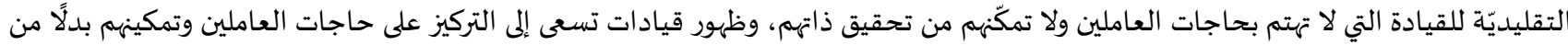

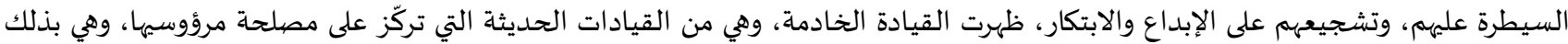

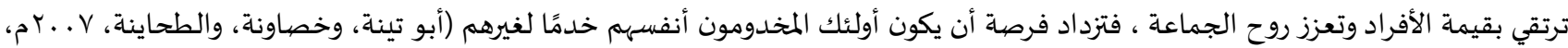

$(1 \varepsilon)-1 \varepsilon$.

وتعدّدت مفاهيم الذكاء العاطفي وتناولها العلماء والباحثون من زوايا مختلفة، تبعًا لنظرتهم وتوجّهاتهم النظرية لهذا المفهوم، حيث توجّه

البعض إلى اعتباره مجموعة من القدرات، بينما توجاه البعض إلى اعتباره مجموعاة من السمات الشخصية والمهارات الاجتماعية والانفعالية.

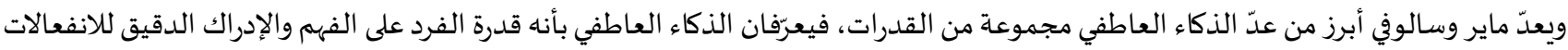

الذاتية والتحكم بها والتعبير عنها، والقدرة على فهم عواطف الآخرين والتعامل معها (Salovey \& Mayer, 1990, p189). 


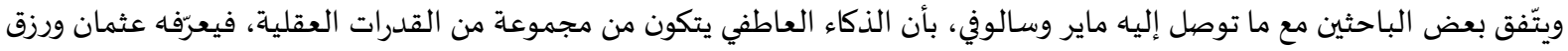

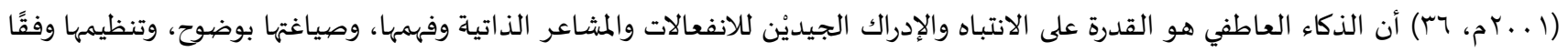

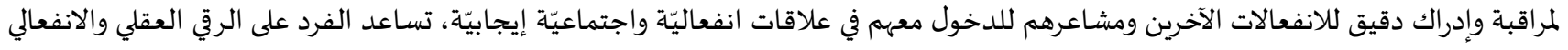
والمهني، وتعلم المزيد من المهارات الإيجابيّة للحياة.

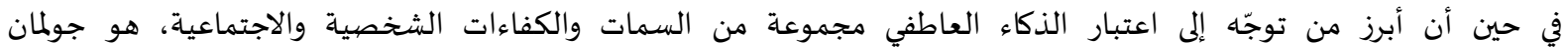

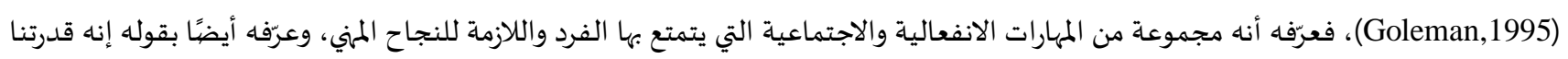

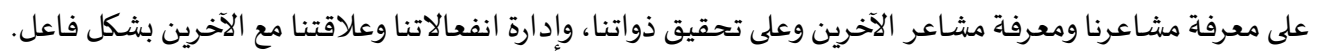

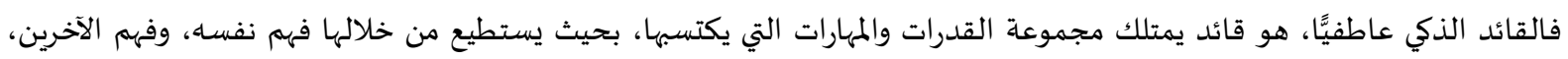

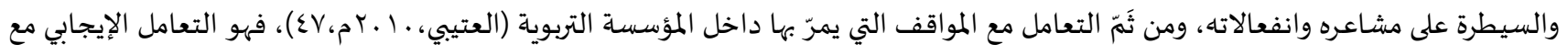

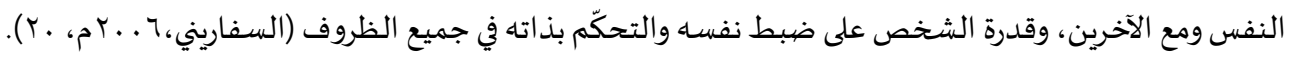

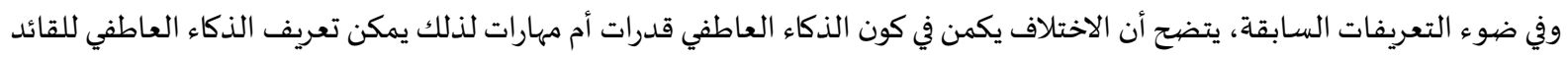

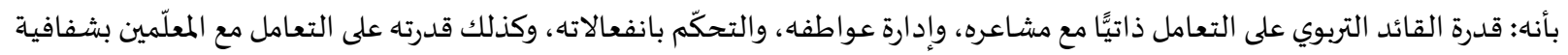

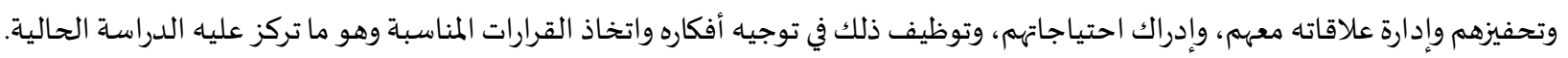

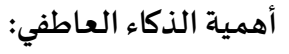

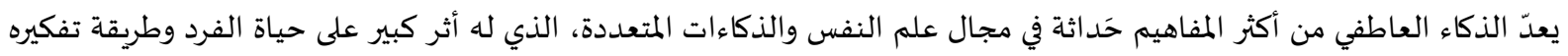

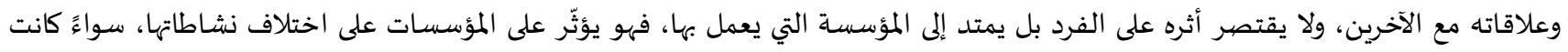

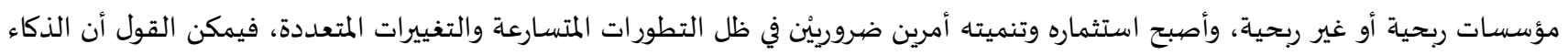

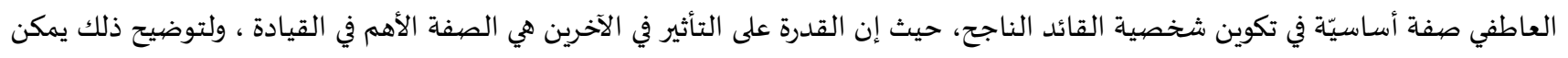

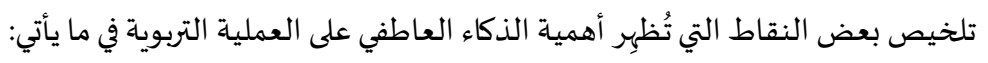
• ميساعد الذكاء العاطفي على استقرار العلاقات الإنسانيّة بين العاملين في المدرسة. يفيد الذكاء العاطفي في زيادة فاعلية القيادة ورفع مستوى أداء القائد.

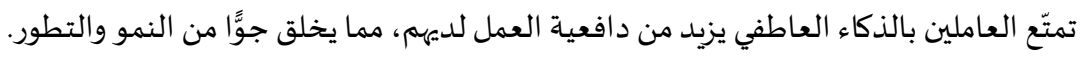

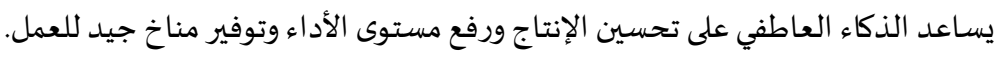
رفح معدلات الطلاب وتحسين سلوكهم وضبط انفعالاتهم.

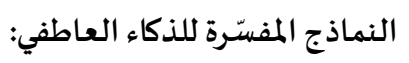

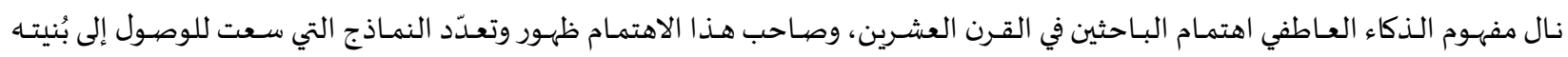

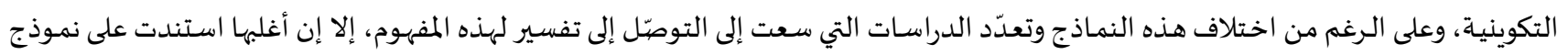

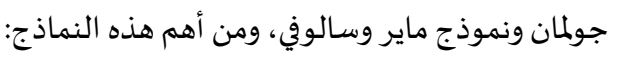
نموذج مايروسالوفي (نموذج القدرة):

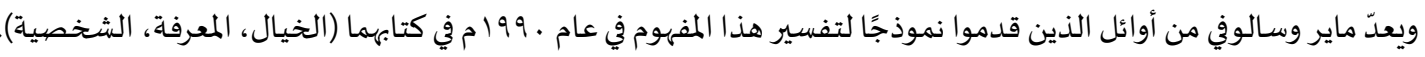

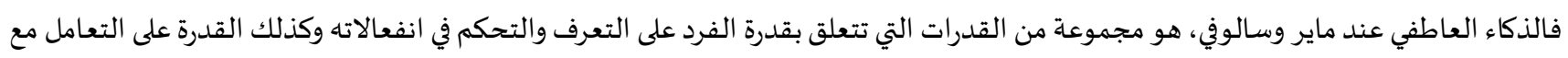

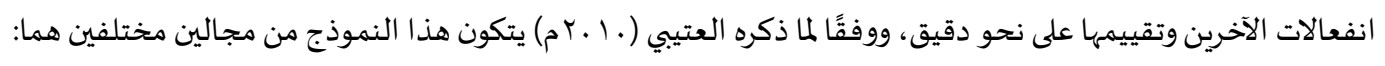

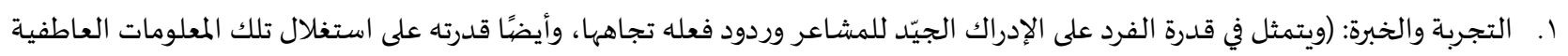

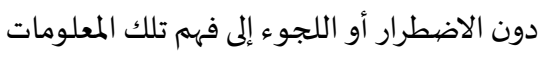
ז. الاستراتيجيات والخطط: (ويتمثل في قدرة الفرد على فهم وإدراك المشاعر واستعداده لذلك دون الحاجة إلى ضرورة تجربة تلك المشاعر الوجدانية). نموذج دانيال جولمان (نموذج مختلط):

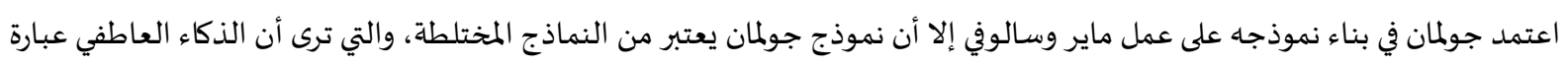

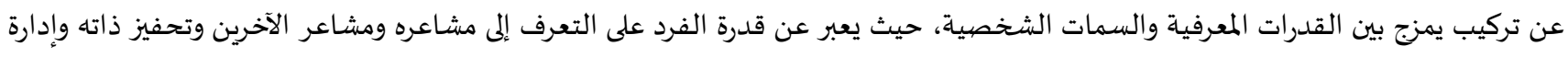

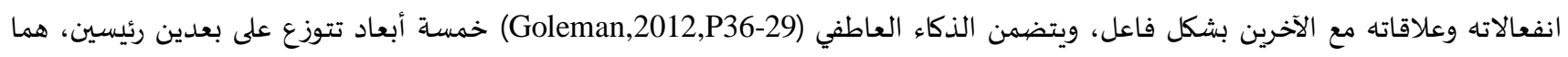
الكفاءة الشخصية والكفاءة الاجتماعية، وهي كالآتي: 
ا. الكفاءة الشخصية: تحدّد هذه الكفاءة، كيف يدير الفرد نفسه؟ وهي تتضمّن ثلاثة أبعاد، هي: الوعي بالذات وتنظيم الذات والدافعية، وكل بعد من هذه الأبعاد تندرج تحته مجموعة من الكفاءات والمهارات، وهي كالآتي:

الوعي بالذات (Self - awareness): وتعني قدرة الفرد على فهم مشاعره الشخصية وإدراكه لحالته النفسية وانفعالاته الداخلية، ويشمل

التقييم الدقيق للذات ، الثقة بالنفس. بالن.

إدارة الانفعالات (Managing Emotions): وتتضمن القدرة على التعامل مع المشاعر، ومقدرته على التحكم بالانفعالات السلبية وتحويلها إلى انفعالات إيجابية ، وتشتمل الكفاءات والمهارات الآتية وهي: ضبط النفس والسيطرة على الانفعالات والدوافع، الجدارة بالثقاة،

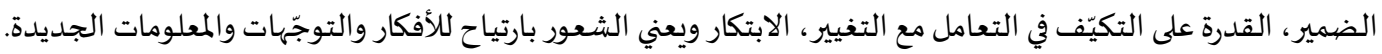
تحفيز النفس والدافعية (Self - Motivation): القدرة على تحفيز الذات والتفكير الإيجابي، وتتضمّن: دافع الإنجاز، الالتزام، المبادرة، التفاؤل. r. الكفاءة الاجتماعية: وتحدّد هذه الكفاءة طريقة تعامل الفرد وعلاقاته مع الآخرين من حيث الاهتمام بحاجاتهم ورغباتهم، وتتكون من بعدين فرعيين، هما:

التعاطف (Empathy): ويعني وعي الفرد وقدرته على الشعور بانفعالات الآخرين والتعامل معها على نحو فاعل، ويتضمن المهارات الآتية:

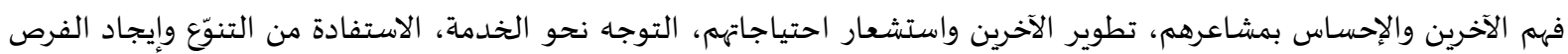
للناس على اختلاف حاجاتهم وأهد افههم. التعامل مع العلاقات (Handling Relationships): ويعني القدرة على التفاعل الإيجابي في المواقف الاجتماعية، وإقامة شبكة واسعة

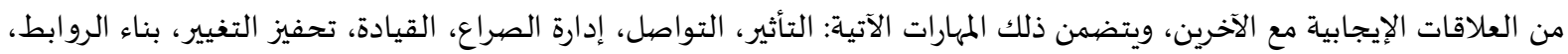

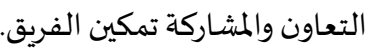

The أما مفهوم القيادة الخادمة فقد ظهرت القيادة الخادمة كمصطلح قيادي في بداية السبعينيات من القرن الماضي، في مقالة بعنوان كتها روبرت غرينليف، الذي كان مديرًا للبحوث والتنمية والتعليم في الشركة الأمريكية للتلفون والتلفراف، وتعدّ رواية (Herman Hesse) المقالة حول أن القائد الخادم هو خادم أولًا، بمعنى أنه يمتلك شعورًا داخليًّا يدفعه لخدمة العاملين، ووضع احتياجاتهم واهتماماتهم والسعي لتطويرهم فوق مصلحتـه. (Greenleaf,2002) فهي قيادة فاعلة تنبثق من الرغبة في مساعدة الآخرين، وجعلها من الأولويات وهو ما يختلف عن نماذج القيادة الهرمية التي يكون فيها القائد في قمة هرم السلطة، على عكس القيادة الخادمة التي يكون موقعه فيها بين المرؤوسين، ويعمل على تطوير مهاراتهم وتفهّم احتياجاتهم ومشاركتهم في

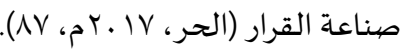

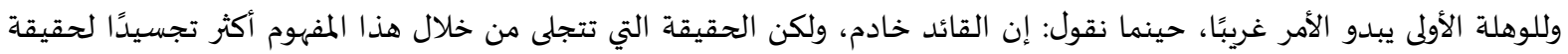

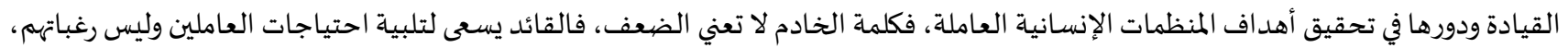
فما يحتاجون إليه قد لا يكون ما يريدون (Hunter,2008,p24).

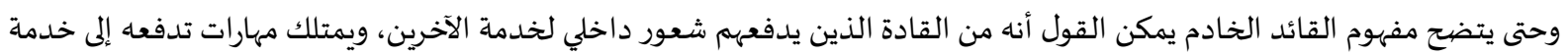

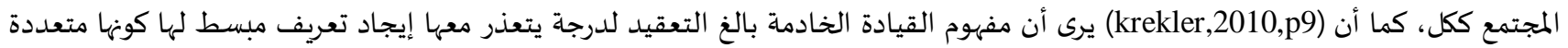

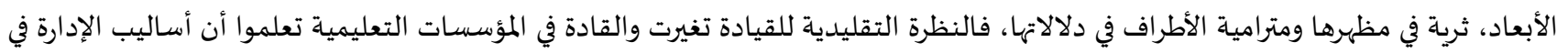

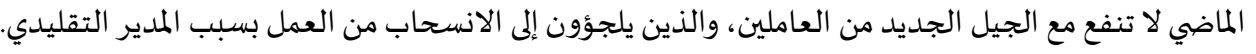

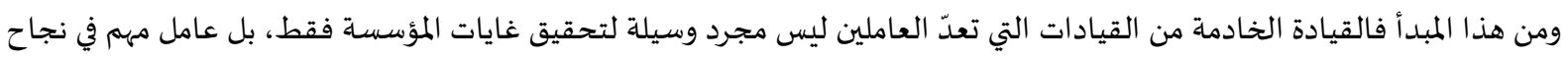
المؤسسة وفشلها، لذلك تسعى إلى احترامه وتلبيه احتياجاته (Hunter,2008,p26)، وتعدّ القيادة الخادمة مدخلاً معاصرًا يلهم العاملين لتجاوز

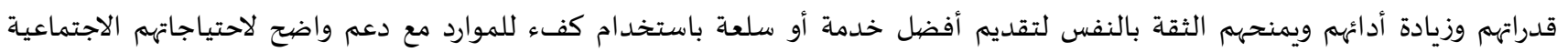

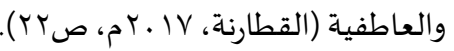

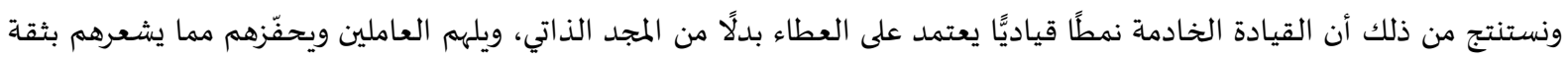

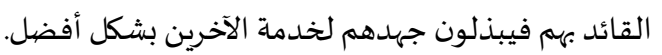
الخصائص والأبعاد الأساسية للقائد الخادم: الخهاد:

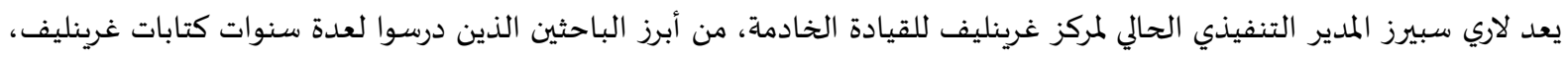
وحدّد نموذج (2010، Spears, p27-29 ) عشر خصائص رئيسة للقيادة الخادمة، وهي: (الاستماع، التعاطف، الشفاء والتلاحم، الوعي، الإقناع، 
تكوين المفاهيم (التصوّر)، البصيرة، الإشراف، الالتزام بتطوير الناس، تكوين المجموعة)، كما تميز نموذج بيج وونغ (Page \& Wong,2000) بأنه أكثر

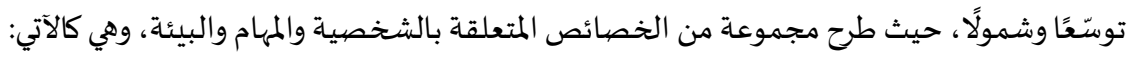

الخصائص الشخصية: وتتمثل في (الاستقامة والتواصل والخدمة).

الخصيائص الموجّهة نحو الآخرين:وتتمثل في (الاهتمام بالآخرين، تمكين الآخرين، تطوير الآخرين).

الخصائص الموجّهة نحو المهام: وتتمثل في (الرؤية، وضع الأهداف، القيادة).

الخصيائص الموجّهة نحو العمليات: وتتمثل في ( النمذجة، بناء الفريق، المشاركة في صنع القرار).

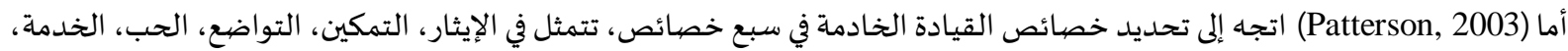

الثقة، الرؤياة.

وقام الباحثان Barbuto \& Wheeler بتحديد خصائص للقيادة الخادمة في خمس خصائص (الإيثار، التلاحم العاطفي، الحكمة،

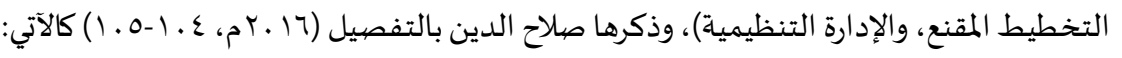

الدعوة للإيثار: يتم تعريف الدعوة للإيثار باعتبارها خيارًا واعيًا لخدمة الآخرين، وتمثّل الرغبة في التأثير بشكل إيجابي على الآخرين من خلال خدمتهم، والتي تعد أمرًا جوهريًّا في القيادة الخادمة. التلاحم العاطفي: ويشمل قدرة القائد على تقديم المساندة والدعم العاطفي للأتباع. الحكمة: وهي القدرة على التقاط الإشارات، أي الملاحظة المستمرة للبيئة والتعرف إلى العواقب المحتملة والآثار المترتبة على ملاحظاتهم. التخطيط المقنع: هو القدرة على استخدام النماذج العقليّة والمنطق لتشجيع التفكير لدى الآخرين.

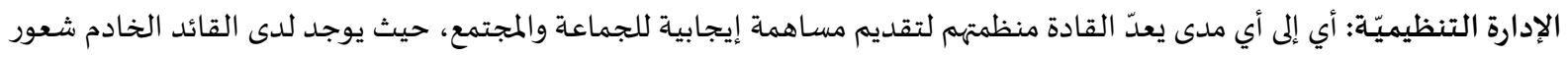
قوي بالمسؤولية الاجتماعية. والدّراسة الحالية تتبنى الأبعاد والخصائص الخمسـة للقيادة الخادمة التي قدمها كلٌّ من (Barbuto \& Wheeler,2006)، لأن هذه الخصائه هائص هي

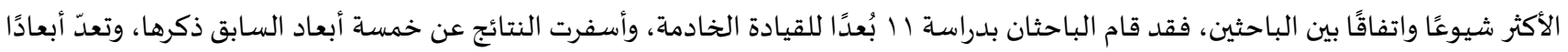

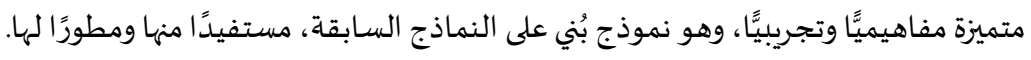
الذكاء العاطفي والقيادة الخادمة تعدّ القيادة من أهم العوامل التي تحقّق النجاح للمؤسسة التعليمية، فهي تتمثل في القدرة على إلهام العاملين والتأثير عليهم ليقدموا أفضل

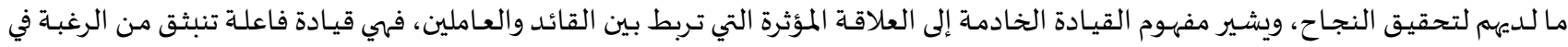
مساعدة الآخرين وجعلهم من الأولويات.

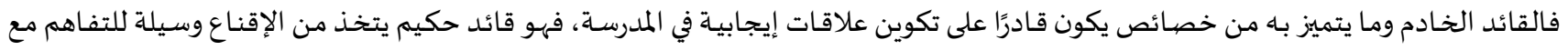

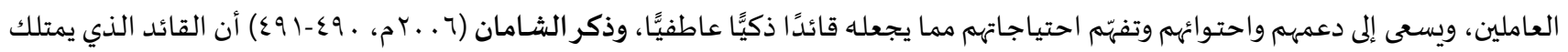

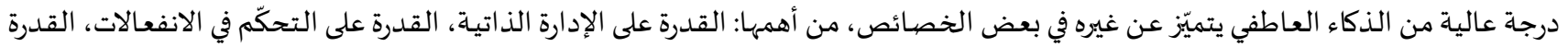

على إدارة العواطف، القدرة على معرفة العواطف، التقمّص الوجداني، القدرة على توجياء العلاقات الإنسانية، القدرة على العملى العلى بجديّة ومثابرة.

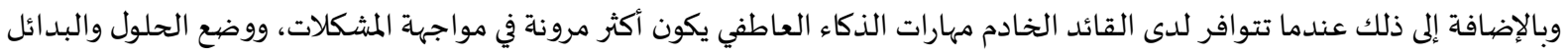

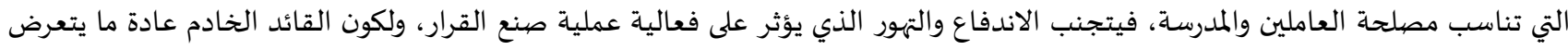

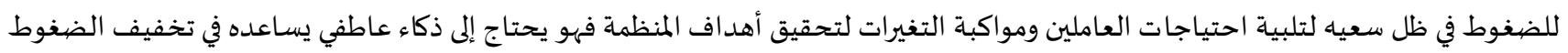
وإدارة الانفعالات.

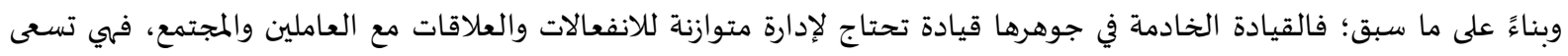

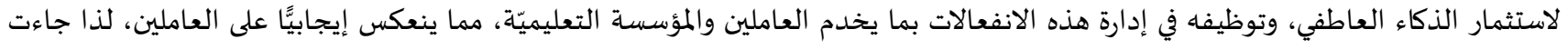

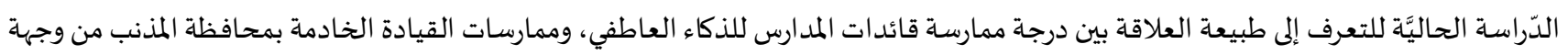
نظر المعلّمات. وهناك العديد من الدراسات المتعلقة بالذكاء العاطفي والقيادة الخادمة التي تتباين في أهدافها ونتائجها عن الدراسة الحالية منها دراسة أحمد

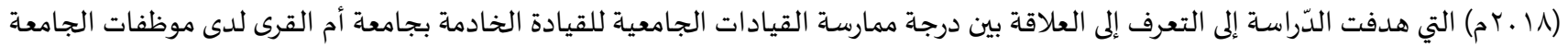

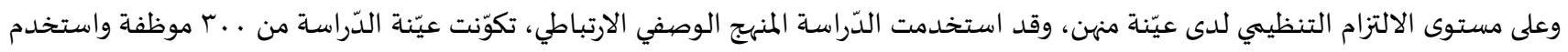

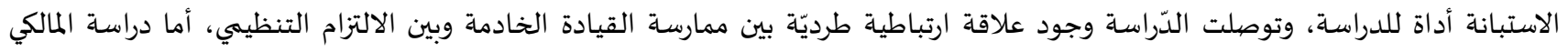
(Vا ـ ام)، سعت الدّراسة إلى التعرف إلى العلاقة بين واقع ممارسة القيادة الخادمة لدى مديري المدارس الثانوية، و درجة الرضيا الوظيفي من وجهة 1 .. 


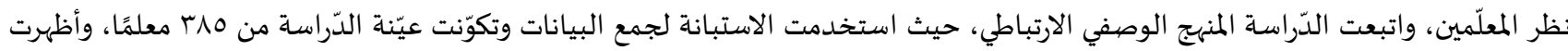

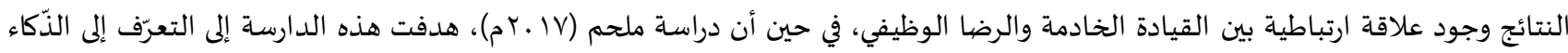

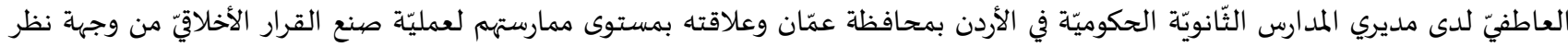

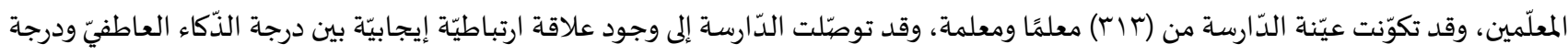

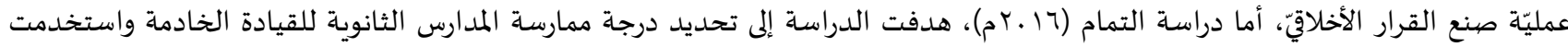

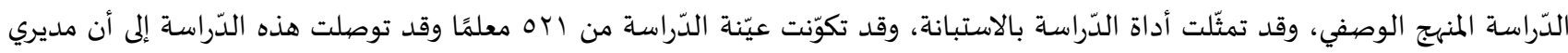

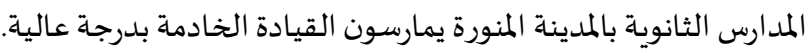

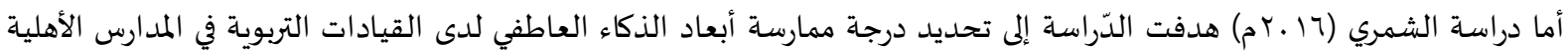

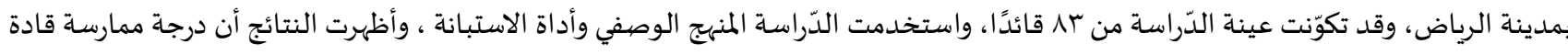

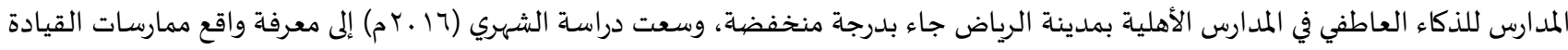

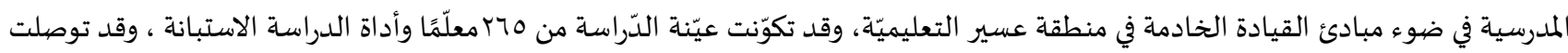

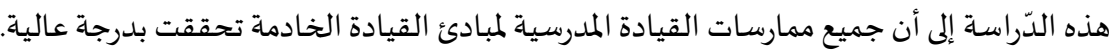

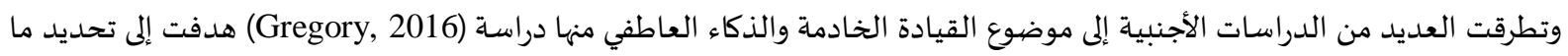

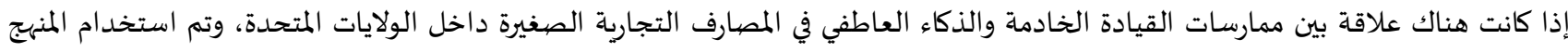

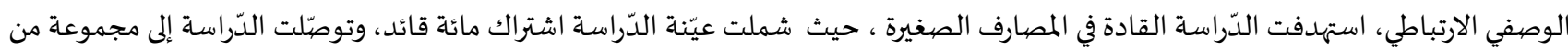

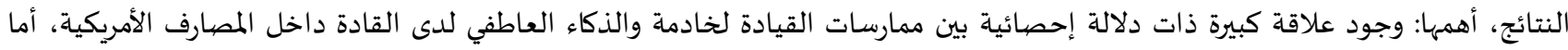

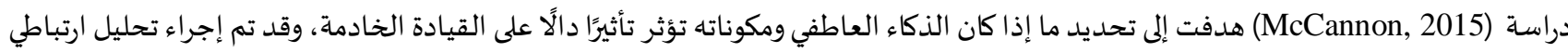

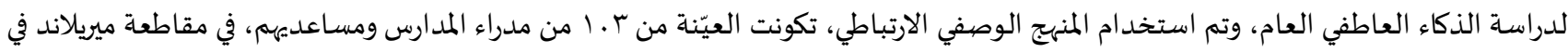

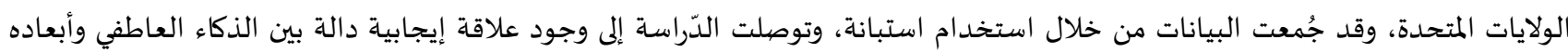

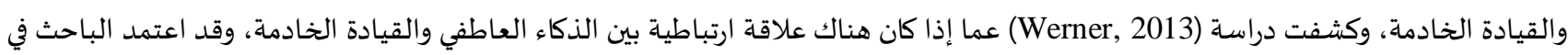

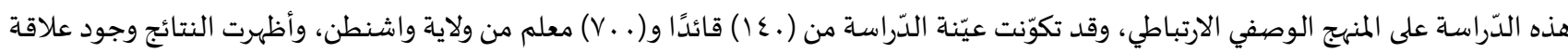
ارتباطية قوية بين القيادة الخادمة والذكاء العاطفي. ومن خلال استعراض الدراسات العببية والأجنبية برزت أهمية الذكاء العاطفي والقيادة الخادمة، وفيما يلي عرض لأبرز النقاط حول الدراسات السابقة:

جو انب الاتفاق والاختلاف بين الدّراسات السابقة والدّراسة الحاليّة:

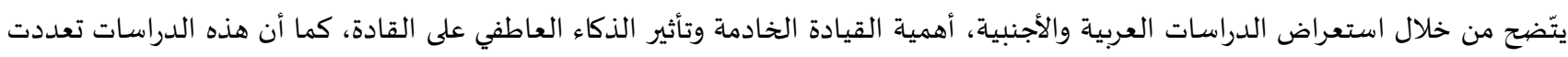

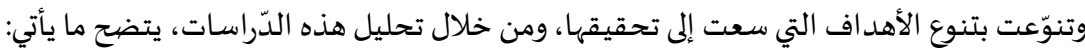

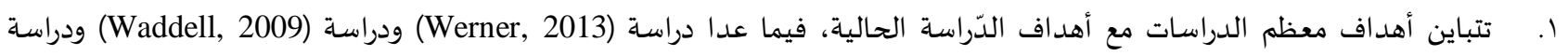

(McCannon, 2015)

r. تختلف الدّراسة الحالية عن دراسة (Werner, 2013) ودراسة (Waddell, 2009) ودراسة (McCannon, 2015) في الأبعاد التي تناولتها

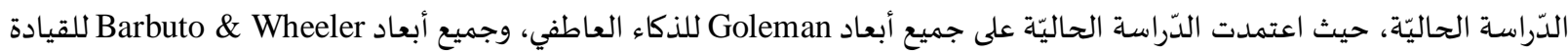

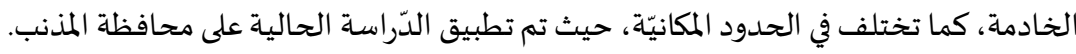

مشكلة الدّراسـة:

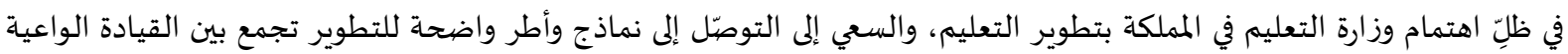

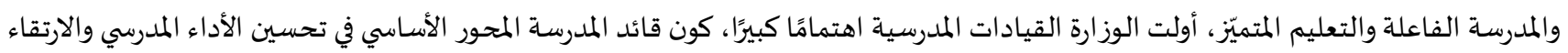

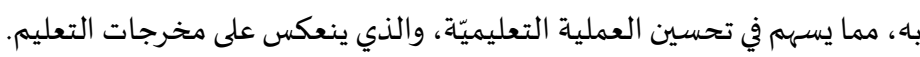

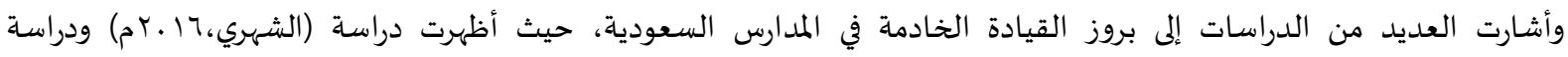

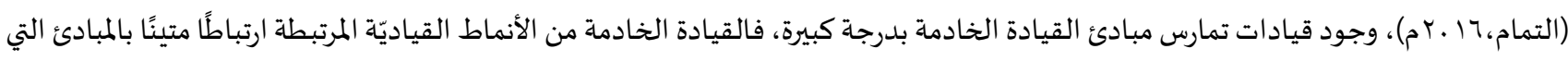

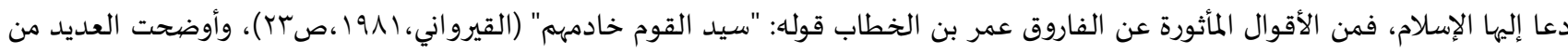

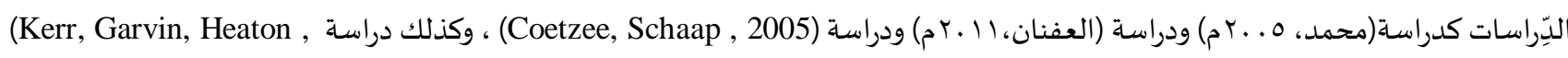




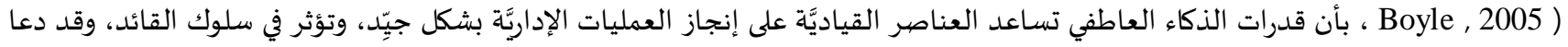

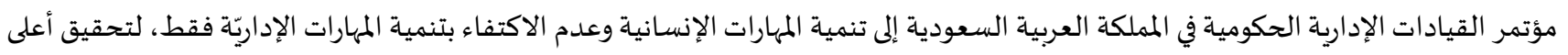

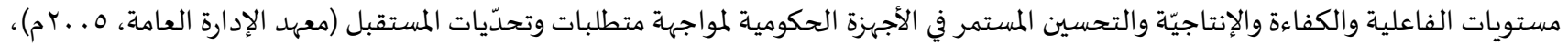

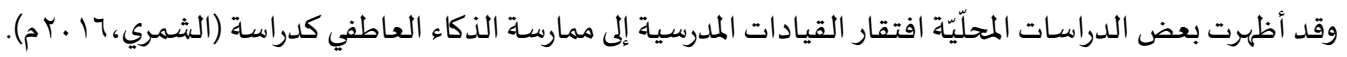

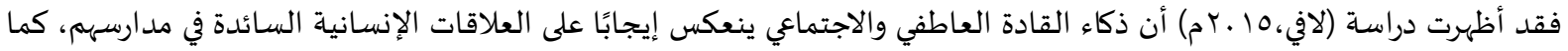

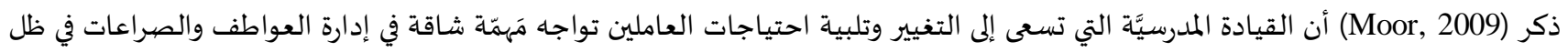

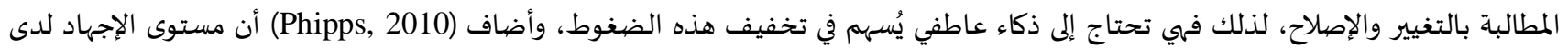

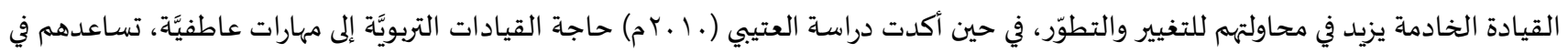

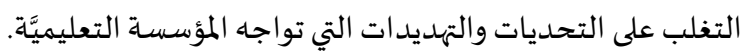

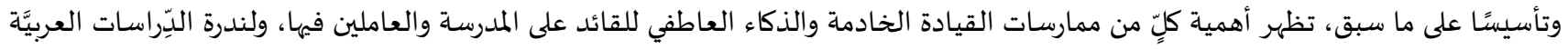

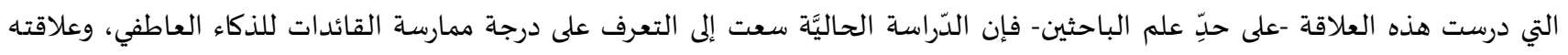
بممارسات القيادة الخادمة، وحاولت الدراسة الإجابة عن التساؤلاتلات التالية التانية:

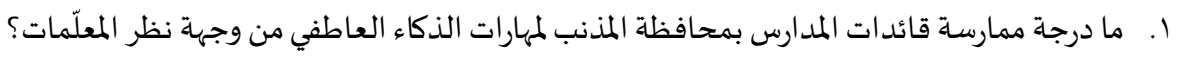

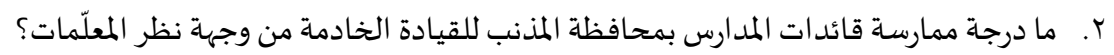

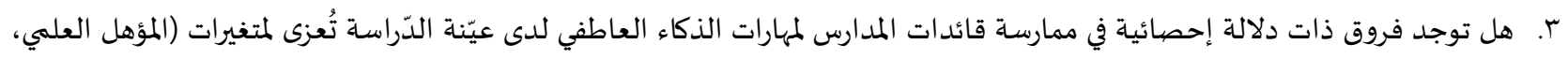

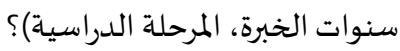
ع. هل توجد فروق ذات دلالة إحصائية في ممارسة قائدات المدارس للقيادة الخادمة لدى عيّنة الدّراسة تُعزى لمتغيرات (المؤهل العلمي، سنوات

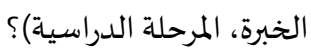
0. ما طبيعة العلاقة بين درجة ممارسة قائدات المدارس لمهارات الذكاء العاطفي ودرجة ممارسة القيادة الخادمة بمحافظة المذنب من وجهة نظر المعلّمات؟

\section{أهداف الدّراسة:}

سعت الدراسة لتحقيق الأهداف التالية:

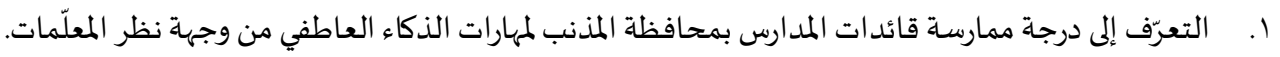

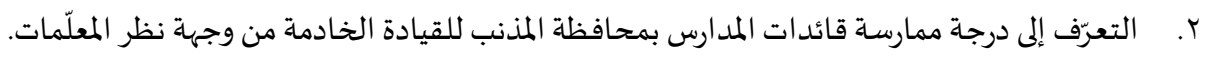

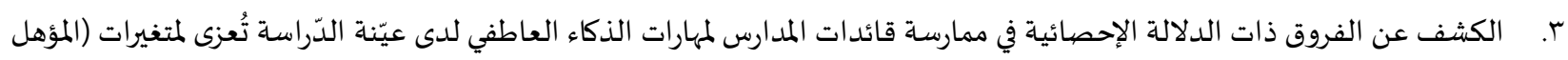

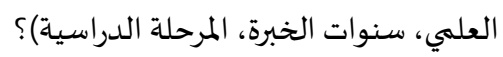
ع. الكشف عن الفروق ذات الدلالة الإحصائية في ممارسة قائدات المدارس للقيادة الخادمة لدى عيّنة الدّراسة تُعزى لمتغيرات (المؤهل العلمي،

$$
\text { سنوات الخبرة، المرحلة الدراسية)؟". }
$$
0. توضيح طبيعة العلاقة بين درجة ممارسة قائدات المدارس لمهارات الذكاء العاطفي ودرجة ممارسة القيادة الخادمة بمحافظة المذنب من وجهة نظر المعلّمات.

\section{أهمية الدّراسة:}

تكمن أهمية الدّراسة في تناولها مفهوم الذكاء العاطفي والقيادة الخادمة، وبشكل أكثر تحديدًا يمكن توضيح أهمية الدّراسة في:

ا. . تستمد هذه الدّراسـة أهميتها النظرية من قلة الأبحاث العربيّة التي تناولت موضوع العلاقة بين الذكاء العاطفي والقيادة الخادمة معًا.

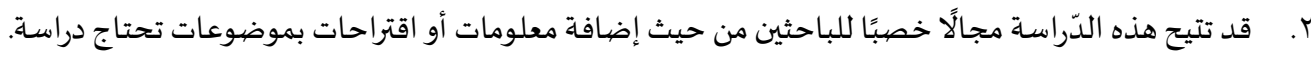

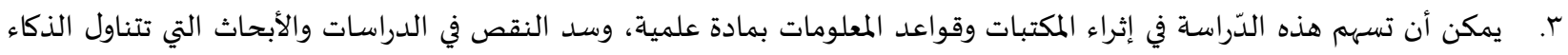
العاطفي والقيادة الخادمة.

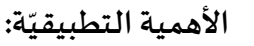


ا. قد تسهم نتائج هذه الدّراسـة في تحديد المشكلات التي تواجه القائدة الخادمة، ومعرفة جـوانب الخلل في توظيف الذكاء العاطفي ومن ثم العمل على حلّها والتغلّب عليها. قد تسهم هذه الدّراسـة وتوصياتها في مساعدة المسئولين والمخططين وأصحاب القرار في المؤسسات التعليمية في تطبيق برامج تسعى لتعزيز ممارسات الذكاء العاطفي وممارسات القيادة الخادمة.

حدلوود اللّرواسـة:

• الحدود الموضوعيّة: تناولت الدّراسة درجة ممارسة القائدات للذكاء العاطفي وفقًا لنموذج جوالمان (الوعي بالذات، إدارة الانفعالات، تحفيز

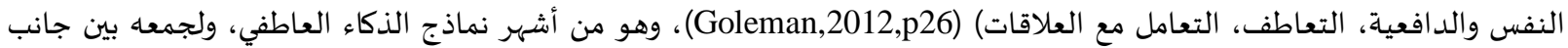

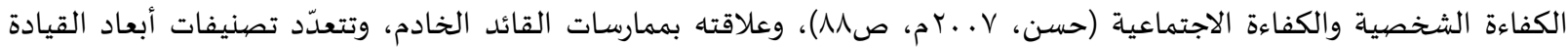
الخادمة، واعتمدت الدّراسة على أبعاد نموذج (Barbuto and Wheeler,2006) ، وهي: (الإيثار، التلاحم العاطفي، الحكمة، التخطيط

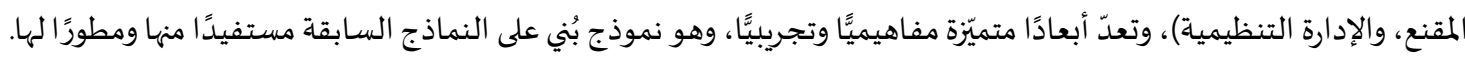
• الحدود المكانيّة: تمّ تطبيق الدّراسة على مدارس التعليم العام في محافظة المذذنب. الحدود البشريّة: تمّّ تطبيق الدّراسة على معلّمات المدارس بمحافظة المذنب.

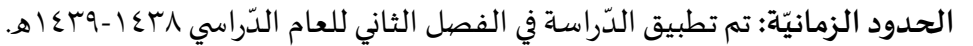

\section{مصطلحات الدّراسة:}

ا.الذكاء العاطفي: ويمكن تعريفها إجرائياً بأهها قدرة القائد التربوي على التعامل ذاتيًّا مع مشاعره، وإدارة عواطفه، والتحكّم بانفعالاته، وكذلك قدرته على التعامل مع المعلّمين بشفافية وتحفيزهم وإدارة علاقاته معهم، وإدراك احتياجاتهم، وتوظيف ذلك فيكاتهات في توجيه أفكاره واتخاذ القرارات

r. القيادة الخادمة: ويمكن تعريفها إجرائياً بأنها مجموعاة من الأساليب التي يمارسها القائد لتمكين العاملين بدلًا من السيطرة عليهم، والتفاني في

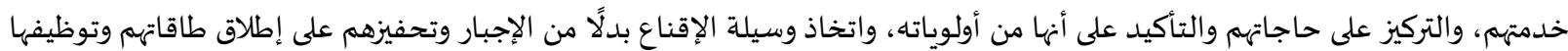

$$
\text { في خدمة المدرسة. }
$$

\section{طريقة الدّراسة وإجراءاتها}

منهج الدّراسة: اعتمدت الدّراسة الحالية على استخدم المنهج الوصفي الارتباطي، والذي يحاول دراسة الذكاء العاطفي وعلاقته بالقيادة الخادمة لدى

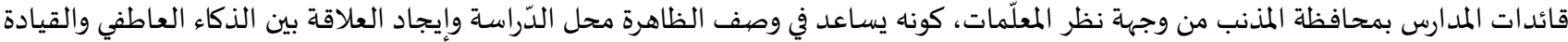

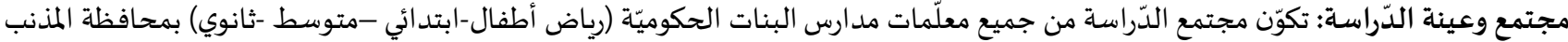

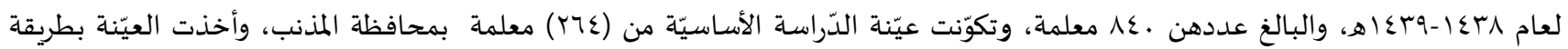
عشوائية، حيث تم استخدام معادلة روبرت ماسون لحساب العينة حيث توزعت عيّنة الدّراسة كالآتي:

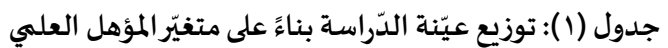

\begin{tabular}{|c|c|c|}
\hline النسبة المئوية & التكرار & المؤهل \\
\hline 11,9 & 0. & دبلوم \\
\hline$\vee \wedge, \varepsilon$ & $r \cdot v$ & بكالوريوس \\
\hline$r, V$ & v & ماجستير فأعلى \\
\hline $1 \ldots$ & TาE & المجموع \\
\hline
\end{tabular}

\begin{tabular}{|c|c|c|}
\hline النسبة المئويَّة & التكرار & الخبرة \\
\hline 11 & rq & أقل من ه سنوات \\
\hline$\varepsilon \varepsilon, r$ & $11 \mathrm{~V}$ & منه إلى أقل من ـ اسنوات \\
\hline$\varepsilon \varepsilon, V$ & 111 & أكثر من · ا سنة \\
\hline $1 \ldots$ & $r 7 \varepsilon$ & المجموع \\
\hline
\end{tabular}


جدول (ץ): توزيع عيّنة الدّراسة بناءً على متغيّر المرحلة الدراسية

\begin{tabular}{|c|c|c|}
\hline النسبة المئوية & التكرار & المرحلة الدراسية \\
\hline$\varepsilon, 9$ & ir & رياض أطفال \\
\hline$r q, 1$ & $1 . r$ & ابتدائي \\
\hline$r \cdot, \Lambda$ & 00 & متوسط \\
\hline ro,r & 94 & ثانوي \\
\hline 1... & rาะ & المجموع \\
\hline
\end{tabular}

أداة الدّراسـة: لتحقيق أهداف الدّراسة تم إعداد الاستبانة اعتمادًا على مراجعة الدراسات السـابقة، وقد تكوّنت الاستبانة من قسمين رئيسين، القسم الأول: وهو عبارة عن المعلومات الشخصية للمستجيب (المؤهل العلمي، الخبرة في التدريس، المرحلة الدراسيّة)، أما القسم الثاني: وهو عبارة عن محاور

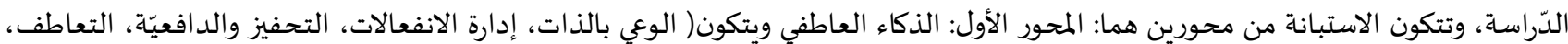

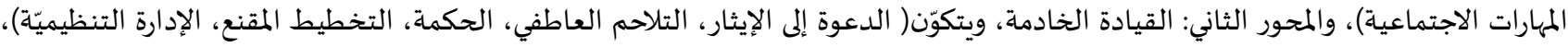

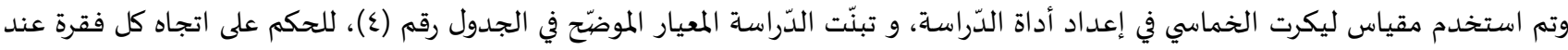
استخدام مقياس ليكرت الخماسي، وذلك بالاعتماد بشكل رئيس على قيمة الوسط الحسابي والوزن النسبي لتحديد مستوى الموافقة على فقرات ومحاور الدّراسـة. جدول (ع): محكّمات تحديد درجة ممارسة مهارات الذكاء العاطفي، ودرجة ممارسة القيادة الخادمة تبعًا للمتوسطات

\begin{tabular}{|c|c|c|c|c|c|}
\hline كبيرة جدًا & كبيرة & متوسطة & ضعيفة & ضعيفة جدًا & درجة التحقّق \\
\hline أكثر من . - & $\varepsilon, 19$ إلى. & r. & 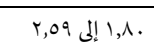 & أقل من VY, & الوسط الحسابي \\
\hline أكثر من ع^^\% & 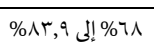 & \%ҮV,q 9 \%०r & \%ب1,9 إلى \% & أقل من 9ro, & الوزن النسبي \\
\hline
\end{tabular}

صهدق وثبات الاستبانة: أولًا: الصيدق: ا. الصددق الظاهري (صبدق المحكّمين):عُرضت الاستبانة في صورتها الأولية على مجموعة من المحكّمين والمحكّمات من أعضياء هيئة التدريس

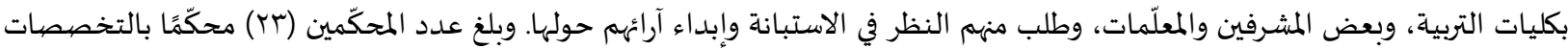

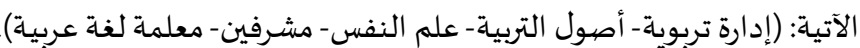

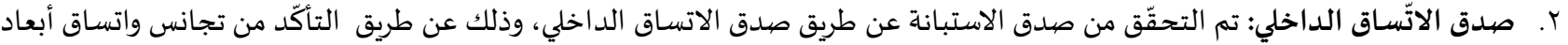

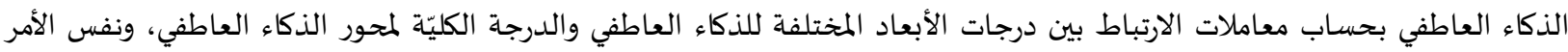
بالنسبة للأبعاد المختلفة للقيادة الخادمة، فكانت معاملات الارتباط كما هي موضّحة بالجدول الآتي:

جدول (0): معاملات الارتباط بين الأبعاد المختلفة للاستبانة والدرجة الكلية للمحور المنتمية إليه

\begin{tabular}{|c|c|}
\hline \multicolumn{2}{|c|}{ درجة ممارسة قائدات المدارس لمهارات الذكاء العاطفي بمحافظة المذنب من وجهة نظر المعلمّات. } \\
\hline بُعد إدارة الانفعالات & بُعد الوعي بالذات \\
\hline$* * .9 . r$ & **. . 9 . \\
\hline بُعد التعاطف & بُعد التحفيز والدافعيّة \\
\hline \multirow[t]{3}{*}{${ }^{* *} \cdot, \wedge \wedge q$} & $* * ., 9 \cdot 1$ \\
\hline & بُعد المهارات الاجتماعيّة \\
\hline & $* *, 9 \cdot \wedge$ \\
\hline \multicolumn{2}{|c|}{ مرجة ممارسة قائدات الممدارس للقيادة الخادمة بمحافظة المدذنب من وجهة نظر المعلّمات. } \\
\hline بُعد التلاحم العاطفي & بُبعد الدعوة إلى الإيثار \\
\hline$* * ., \wedge \varepsilon r$ & **.,११. \\
\hline بُعد التخطيط المقنع & بُعد الحكمة \\
\hline \multirow[t]{3}{*}{ **.,9r. } & **.,q.r \\
\hline & بُعد الإدارة التنظيميّة \\
\hline & ${ }^{* *} .$, , \. \\
\hline
\end{tabular}

الثبات: تمّ التحقّق من ثبات درجات الأبعاد المختلفة للاستبانة الحالية باستخدام معامل ثبات ألفا كرونباخ فكانت معاملات الثبات، كما هو موضح بالجدول الآتي: 
جدول (7): معاملات ثبات ألفا كرونباخ لاستبانة الذكاء العاطفي والقيادة الخادمة

\begin{tabular}{|c|c|c|c|}
\hline \multicolumn{4}{|c|}{ الذكاء العاطفي } \\
\hline التحفيزوالدافعيّة & إدارة الانفعالات & الوعي بالذات & البعد البعد \\
\hline . А А & $\cdot, \wedge \Lambda \varepsilon$ & $\cdot, \mathrm{V} \varepsilon$. & معامل الثبات \\
\hline المحور ككل & المهارات الاجتماعيّة & التعاطف & البُعد \\
\hline$\cdot, 9 T V$ & $\cdot, \lambda V T$ & .,91\% & معامل الثبات \\
\hline \multicolumn{4}{|c|}{ القيادة الخادمة } \\
\hline الحكمة & التلاحم العاطفي & الدعوة إلى الإيثار & 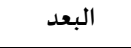 \\
\hline$\cdot, 911$ & $\cdot, 97 \mathrm{~V}$ & $\cdot, 9 r \varepsilon$ & معامل الثبات \\
\hline المحور ككل & الإدارة التنظيميّة & التخطيط المقنع & البعد \\
\hline$\cdot, 9 \curlyvee \wedge$ & ·, $9 \leqslant$ r & •, qrV & معامل الثبات \\
\hline
\end{tabular}

يتّضح من الجدول السابق أن لمحاور الاستبانة وأبعادها المختلفة معاملات ثبات جيدة ومقبولة إحصائيَّا، ومما سبق يتضح أن للاستبانة مؤشرات

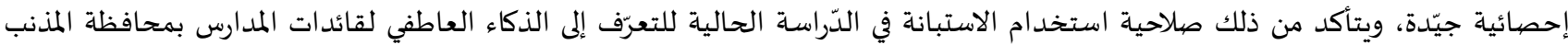
وعلاقته بالقيادة الخادمة من وجهة نظر المعلّمات.

\section{نتائج أسئلة الدراسة ومناقشتها: أولاً: نتائج السؤال الأول ومناقشتها:}

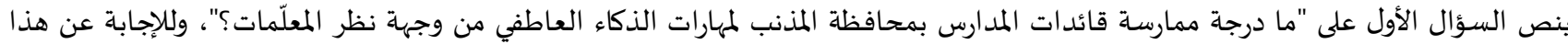

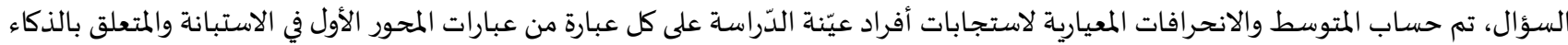

العاطفي، فكانت النتائج كما يلي:

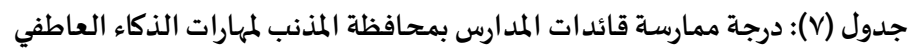

\begin{tabular}{|c|c|c|c|c|}
\hline الترتيب & درجة التحقق & الانحراف المعياري & المتوسط & درجة ممارسة قائدات المددارس بمحافظة المذذنب لمهارات الذكاء العاطفي \\
\hline$\varepsilon$ & كبيرة & $\cdot, \mathrm{V} r$ & r,Avq & البُعد الأول: الوعي بالذات. \\
\hline$\circ$ & كبيرة & $\cdot, \Lambda$ & $r, \wedge \vee\urcorner$ & البُعد الثاني: إدارة الانفعالات. \\
\hline 1 & كبيرة & $\cdot, 17$ & $r, 99$ & البُعد الثالث: التحفيز والدافعية. \\
\hline r & كبيرة & . $9 \mathrm{r}$ & $r, \Lambda$ & البُعدد الرابع: التعاطف. \\
\hline r & كبيرة & $\cdot, \Lambda$ & r,qr & البُعد الخامس: المهارات الاجتماعية. \\
\hline \multicolumn{2}{|c|}{ كبيرة } & $\cdot, \mathrm{V} 7$ & $r, 91$ & الدرجة الكلية لممارسة مهارات الذكاء العاطفي \\
\hline
\end{tabular}

يتضح من الجدول السـابق أن: درجة ممارسة قائدات المدارس بمحافظة المذنب لمهارات الذكاء العاطفي تحققت بدرجة كبيرة، حيث بلغ

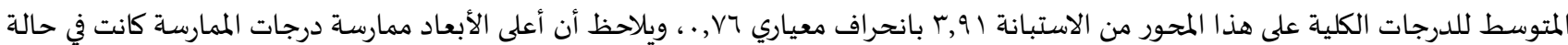

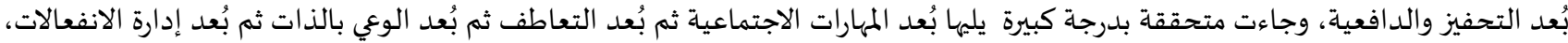

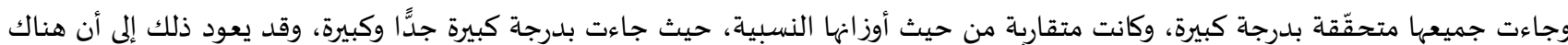
ارتباطًا وثيقًا بين المجالات الخمسة للذكاء العاطفي، فكل مجال يتكامل مع المجال الآخر لتكوّن منظومة الذكاء العاطفي. وحصول بُعده التحفيز

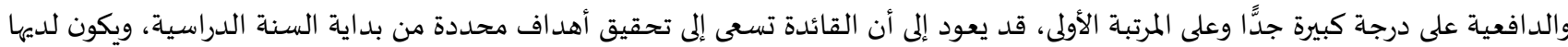

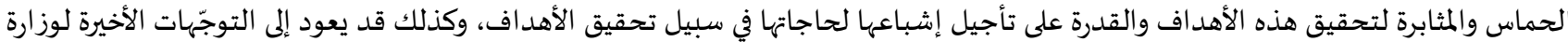

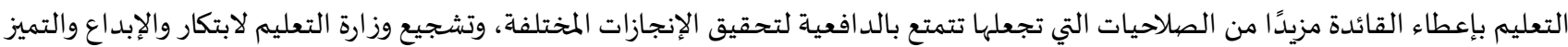
وتخصيص مسابقات لتكريم القادة المتميّزين. ويتضح من الجدول السـابق حصول بُعد إدارة الانفعالات على درجة كبيرة واحتل المرتبة الخامسة والأخيرة، وقد يعود ذلك لقلّة الدورات

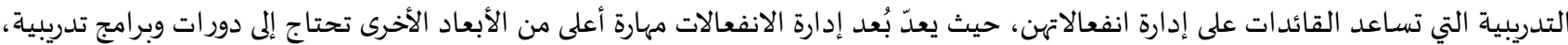
وكذلك قد يعود ذلك إلى كثرة الضغوط والمشاكل الإدارية التي تواجه القائدة.

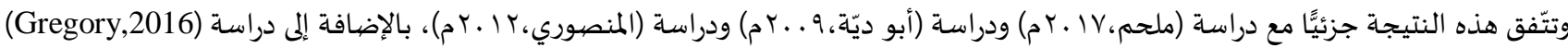

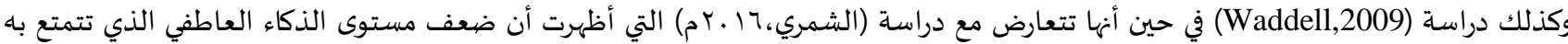

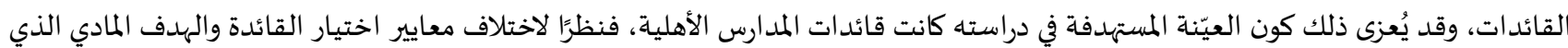


تسعى المدارس الأهلية إلى تحقيقه بأعلى قدر بغض النظر عن العلاقات الإنسانية، أي تحرص عادة على رفع مستوى الإنتاجية بغض النظر عن مشـاعر المعلمات.

ثانياً: نتائج السؤال الثاني ومناقشتها:

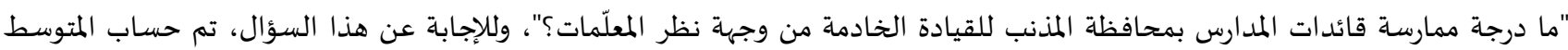
والانحرافات المعيارية لاستجابات أفراد عيّنة الدّراسة على كلّ عبارة من عبارات المحور الثاني في الاستبانة، والمتعلق بالقيادة الخادمة، فكانت النتائج كما يأتي:

جدول (^): درجة ممارسة قائدات المدارس بمحافظة المذنب للقيادة الخادمة

\begin{tabular}{|c|c|c|c|c|}
\hline الترتيب & درجة التحقّق & الانحراف المعياري & المتوسط & مرجة ممارسة قائدات المدارس بمحافظة المذنب للقيادة الخادمة \\
\hline$\varepsilon$ & كبيرة & $1,1 T$ & $r, \varepsilon \varepsilon$ & البُعدد الأول: الدعوة إلى الإيثار. \\
\hline 0 & متوسطة & $1, \mathrm{TV}$ & $r, 11$ & البُعد الثاني: التلاحم العاطفي. \\
\hline r & كبيرة & $\cdot, 9 \mathrm{~V}$ & $r, v 7$ & البُعد الثالث: الحكمة. \\
\hline$r$ & كبيرة & $1, . V$ & $r, \eta \Lambda$ & البُعد الرابع: التخطيط المقنح. \\
\hline 1 & كبيرة &., 99 & $r, 90$ & البُعد الخامس: الإدارة التنظيمية. \\
\hline \multicolumn{2}{|c|}{ كبيرة } & $\cdot, 91$ & $r, 09$ & الدرجة الكلية لممارسة القيادة الخادمة. \\
\hline
\end{tabular}

ويتضح من الجدول السابق أن: درجة ممارسة قائدات المدراس بمحافظة المذنب للقيادة الخادمة من وجهة نظر المعلّمات متحققة بدرجة

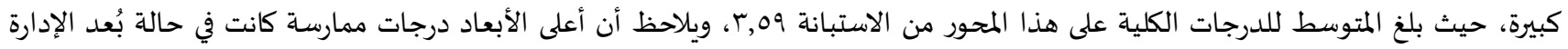

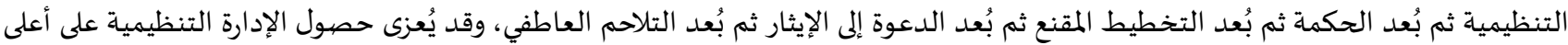

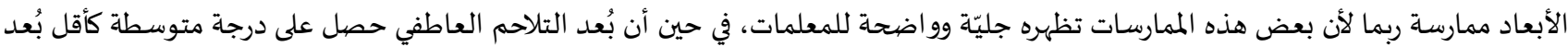
ممارسة من بين أبعاد القيادة الخادمة، والذي قد يُعزى إلى كون المشاعر يصعب قياسها وتحتاج إلى وقت، وبعضها يحتاج إلى مواقف تثبتها، وتتفق هذه إنها

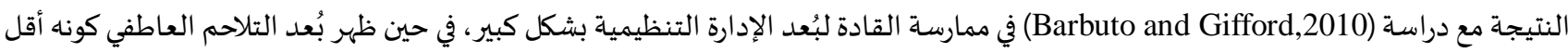

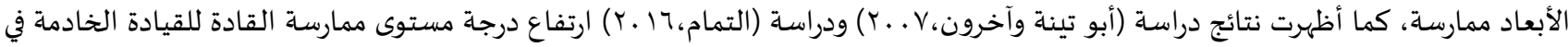

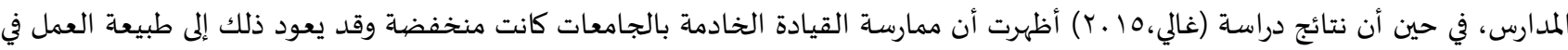

الجامعات والتي تختلف عن البيئة المدرسية.

ثالثاً: نتائج السؤال الثالث ومناقشتها: "هل توجد فروق ذات دلالة إحصائية في ممارسة قائدات المدارس لمهارات الذكاء العاطفي لدى عيّنة الدّراسة تُعزى لمتنيرات (المؤهل العلمي، سنوات

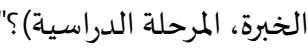
ا. بالنسبة لمتغيّر المؤهل العلمي: تم استخدام تحليل التباين أحادي الاتجاه One Way ANOVA في الكشف عن دلالة الفروق في استجابات المعلّمات عيّنة الدّراسة حول الذكاء العاطفي والراجعة لاختلاف المؤهل العلمي (دبلوم - بكالوريوس - ماجستير فأعلى)، فكانت النتائج كما هي

موضحة بالجدول الآتي:

جدول (9): دلالة الفروق في استجابات عيّنة الدّراسة حول درجة ممارسة قائدات المدارس للذكاء العاطفي تبعًا لاختلاف المؤهل العلمي

\begin{tabular}{|c|c|c|c|c|c|c|}
\hline مستوى الدلالة & قيمةF & متوسط المربعات & درجات الحرية & مجموع المربعات & مصدر التباين & درجة ممارسة قائدات المدارس للذكاء \\
\hline \multirow{3}{*}{ غير دالة } & \multirow{3}{*}{ • rar } &.,$Y Y q$ & r & $\cdot, £ 09$ & بين المجموعات & \multirow[t]{3}{*}{ محور الذكاء العاطفي } \\
\hline & &., $0 \wedge \varepsilon$ & r71 & 10r, rar & داخل المجمموعات & \\
\hline & & & rדז & 10r, 10Y & الكلي & \\
\hline
\end{tabular}

يتضح من الجدول السابق أنه: لا توجد فروق ذات دلالة إحصائية في استجابات المعلّمات حول ممارسة قائدات المدارس للذكاء العاطفي راجعة لاختلاف المؤهل العلمي للمعلمات.

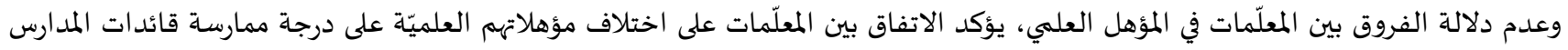

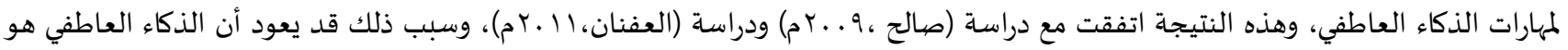

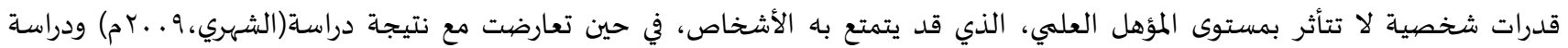

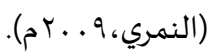


r. بالنسبة لمتغيّز سنوات الخبرة: تمّ استخدام تحليل التباين أحادي الاتجاه One Way ANOVA في الكشف عن دلالة الفروق في استجابات

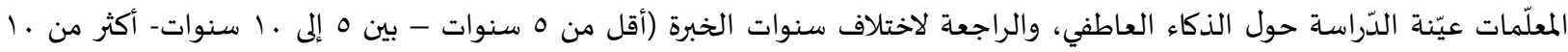

$$
\text { سنوات)، فكانت النتائج كما هي موضحة بالجدول الآتي: }
$$

جدول ( ـ (): دلالة الفروق في استجابات عيّنة الدّراسة حول درجة ممارسة قائدات المدارس للذكاء العاطفي تبعًا لاختلاف سنوات الخبرة

\begin{tabular}{|c|c|c|c|c|c|c|}
\hline مستوى الدلالة & قيمة Faم & متوسط المربعات & درجات الحرية & مجموع المربعات & مصدر التباين & درجة ممارسة قائدات المدارس للذكاء \\
\hline \multirow[t]{3}{*}{., .1} & \multirow[t]{3}{*}{,$\wedge 77$} & $r, V \varepsilon \wedge$ & $r$ & $0, \sum 90$ & بين المجموعات & \multirow[t]{3}{*}{ محور الذكاء العاطفي } \\
\hline & &., 070 & r71 & IEV, rov & داخل المجموعات & \\
\hline & & & r7ז & $10 \mathrm{r}, 10 \mathrm{r}$ & الكلي & \\
\hline
\end{tabular}

وللتعرّف إلى الفروق ذات الدلالة بين مجموعات سنوات الخبرة المختلفة في ممارسة مهارات الذكاء العاطفي، تمّ استخدام اختبار أقل فرق دال LSD كأسلوب للمقارنات البُعدية في حالة دلالة تحليل التباين أحادي الاتجاه، كما هو موضح بالجدول الجدول الآتي:

جدول (1 ا): المقارنات البُعدية بين استجابات عيّنة الدّراسة حول درجة ممارسة قائدات المدارس لمهارات الذكاء العاطفي تبعًا لاختلاف سنوات الخبرة

\begin{tabular}{|c|c|c|c|}
\hline بين 0... س سنوات (م/r,YV=) & أقل من 0سنوات (م=Y & سنوات الخبرة & \multirow{3}{*}{ الذكاء العاطفي } \\
\hline & $*_{.}^{*}, \varepsilon 01$ & بين 0. ــ اسنوات (م=r,VV) & \\
\hline$* ., 19 \mathrm{~V}$ & & . سنوات فأكثر (م= (r,qV) & \\
\hline
\end{tabular}

يتضح من الجدولين السـابقين أنه: توجد فروق دالة إحصائيًا عند مستوى ا.., • في ممارسة مهارات الذكاء العاطفي لدى قائدات المدارس

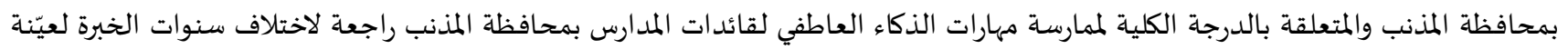

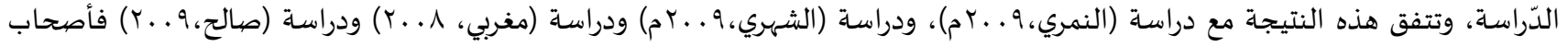

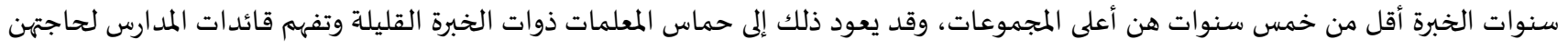

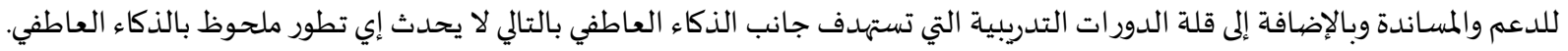

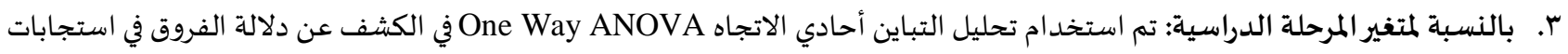

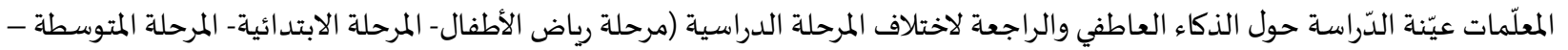

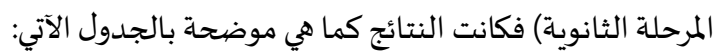

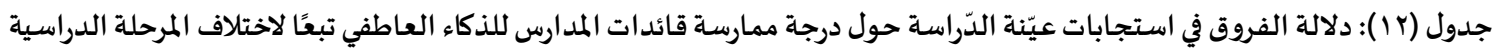

\begin{tabular}{|c|c|c|c|c|c|c|}
\hline 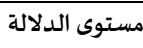 & 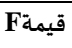 & متوسط المربعات & 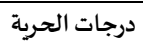 & 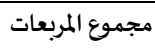 & مصدر التباين & درجة ممارسة قائدات المدارس للذكاء العاطفي \\
\hline \multirow[t]{3}{*}{ غير دالة } & \multirow[t]{3}{*}{ T,YYT } & 1, THY & $r$ & $r, 990$ & بين المجموعات & \multirow[t]{3}{*}{ 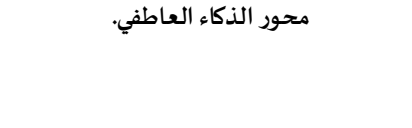 } \\
\hline & &., $0 \mathrm{VT}$ & r. & $\mid \varepsilon \wedge, \wedge \circ V$ & داخل المجمموعات & \\
\hline & & & אדו & $10 \mathrm{r}, 10 \mathrm{r}$ & الكلي & \\
\hline
\end{tabular}

يتضح من الجدول (r ا) أنه: أنه لا توجد فروق دالة إحصائيًا في ممارسة مهارات الذكاء العاطفي (الدرجة الكلية) راجعة لاختلاف المرحلة الدراسية وهو ما يختلف مع دراسة (هبري، IV . Y) التي أظهرت وجود فروق راجعة لاختلاف المرحلة الدراسية. رابعًا: نتائج السؤال الر ابع ومناقشتها: هل توجد فروق ذات دلالة إحصائية في ممارسة قائدات المدارس للقيادة الخادمة لدى عيّنة الدّراسة تُعزى لمتغيرات (المؤهل العلمي، سنوات الخبرة، المرحلة الدراسية) ؟. ا. بالنسبة لمتغير المؤهل العلمي: تم استخدام تحليل التباين أحادي الاتجاه One Way ANOVA في الكشف عن دلالة الفروق في استجابات

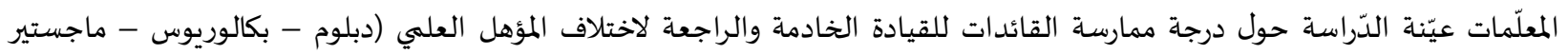

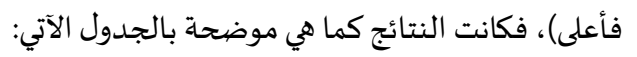


جدول ( سا ): دلالة الفروق في استجابات عيّنة الدّراسة حول درجة ممارسة قائدات المدارس للقيادة الخادمة تبعًا لاختلاف المؤهل

\begin{tabular}{|c|c|c|c|c|c|c|}
\hline مستوى الدلالة & ق قيمة F F & متوسط المربعات & درجات الحرية & مجموع المربعات & مصدر التباين & القيادة الخادمة \\
\hline \multirow[t]{3}{*}{ غير دالة } & \multirow[t]{3}{*}{. $9 \pi$} & $\cdot, \wedge 9$. & $r$ & I, ২ᄉ. & بين المجموعات & \multirow[t]{3}{*}{ تحور القيادة الخادمة } \\
\hline & &., $90 \leqslant$ & (7) & $r\{\wedge, \Lambda M \Lambda$ & داخل المجمموعات & \\
\hline & & & אדו & ro., 7TV & الكلي & \\
\hline
\end{tabular}

م دالة إحصائيًا عند مستوى دلالة 0.05 =

يتضح من الجدول السـابق أنه: لا توجد فروق ذات دلالة إحصائية في استجابات المعلّمات حول ممارسة قائدات المدارس للقيادة الخادمة راجعة لاختلاف المؤهل العلمي للمعلمات، وعدم دلالة الفروق بين المعلّمات في المؤهل العلمي يؤكد الاتفاق بين المعلّمات على اختلاف مؤهلاتهم العلمية على

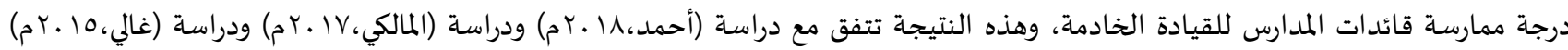

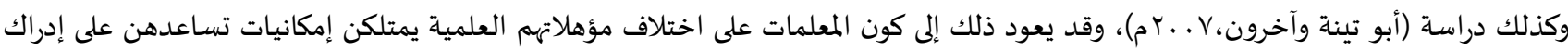
النمط القيادي بغض النظر عن المؤهل.

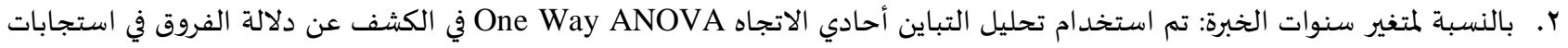

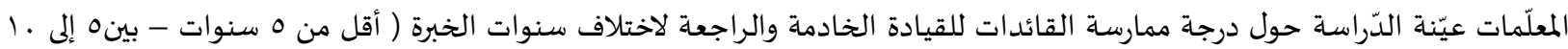

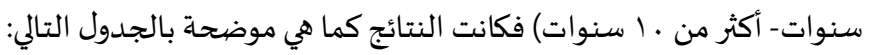

جدول ( ع ): دلالة الفروق في استجابات عيّنة الدّراسة حول درجة ممارسة قائدات المدارس القيادة الخادمة تبعًا لاختلاف سنوات الخبرة

\begin{tabular}{|c|c|c|c|c|c|c|}
\hline مستوى الدلالة & قيمة F & متوسط المربعات & درجات الحرية & مجموع المربعات & مصبدر التباين & درجة ممارسة قائدات المدارس القيادة \\
\hline \multirow[t]{3}{*}{ غير دالة } & \multirow[t]{3}{*}{ r,90r } & T,VVY & r & $0,0 \leq \varepsilon$ & بين المجموعات & \multirow[t]{3}{*}{ محور القيادة الخادمة } \\
\hline & & . & Y71 & $T \leq 0,1 T r$ & داخل المجموعات & \\
\hline & & & זור & To., TTV & الكلي & \\
\hline
\end{tabular}

يتضح من الجدول السابق أنه: لا توجد فروق دالة إحصائيًا في ممارسـة القائدات للقيادة الخادمة المتعلقة بالدرجة الكلية راجعة لاختلاف سنوات

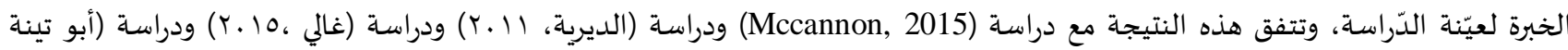

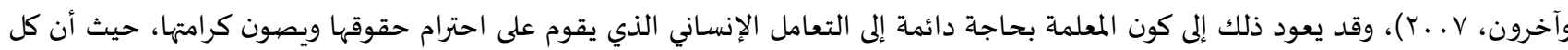
المعلمات يطمحون إلى العمل داخل أجواء قيادية تسودها العلاقات الإنسانية.

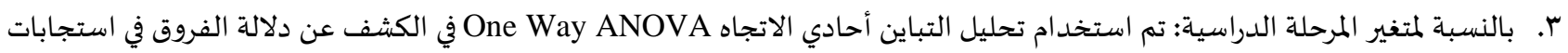
المعلّمات عيّنة الدّراسة حول درجة ممارسة قائدات المدارس للقيادة الخادمة والراجعة لاختلاف المرحلة الدراسية (مرحلة رياض الأطفال- المرحلة

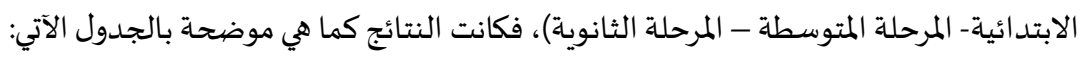

جدول (10): دلالة الفروق في استجابات عيّنة الدّراسة حول درجة ممارسة قائدات المدارس القيادة الخادمة تبعًا لاختلاف المرحلة الدراسية

\begin{tabular}{|c|c|c|c|c|c|c|}
\hline مستوى الدلالة & ق قيمة F & متوسط المربعات & درجات الحرية & مجموع المربعات & مصدر التباين & درجة ممارسة قائدات المدارس للقيادة \\
\hline \multirow[t]{3}{*}{ دالة احصائيا } & \multirow[t]{3}{*}{$r, . \varepsilon £ *$} & r,Aro & r & $1,0.7$ & بين المجموعات & \multirow[t]{3}{*}{ محور القيادة الخادمة } \\
\hline & & . & r. & $r\{r,|7|$ & داخل المجموعات & \\
\hline & & & rit & ro.,7TV & الكلي & \\
\hline
\end{tabular}

a = 0.05 دالة إحصائيًا عند مستوى دلالة*

جدول(17 ): المقارنات البُعدية بين استجابات عيّنة الدّراسة حول درجة ممارسة قائدات المدارس للقيادة الخادمة تبعًا لاختلاف المرحلة الدراسية

\begin{tabular}{|c|c|c|c|c|}
\hline 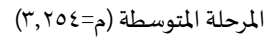 & المرحلة الابتدائية (م=V. ع, r) & 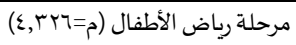 & المرحلة الدراسية & القيادة الخادمة \\
\hline & & $*,, 7 . \leqslant 7$ & المرحلة الابتدائية (م=1,r,r) & \\
\hline & & $* .$, N $0 \mathrm{~V}$ & المرحلة المتوسطة (م=9,rq) & \\
\hline & & $*_{\cdot}^{*}, \mathrm{~V} \cdot \mathrm{Vr}$. & المرحلة الثانوية (د=-r,00) & \\
\hline
\end{tabular}


يتضح من الجدولين السابقين أنه: توجد فروق دالة إحصائيًا عند مستوى ه . . . في ممارسة القائدات للقيادة الخادمة الدرجة الكلية راجعة لاختلاف

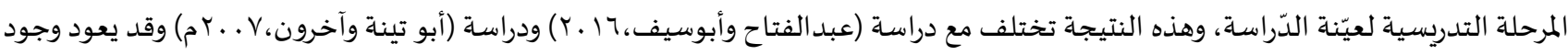
الفروق كون قادة المدارس في قمة الهرم المدرسة فهم يتأثرون بما يواجهون من سلوك الطلبة في المراحل المختلفة ومرحلة المراهقة وحاجتهم إلى الحزم في

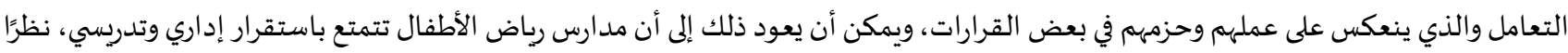

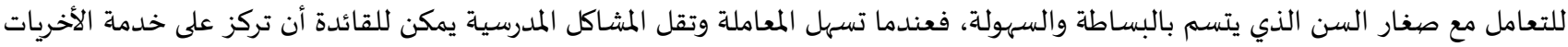
وتسعى لحل مشكلاتهن.

خامسًا: نتائج السؤال الخامس مئلاتن ومناقشتها:

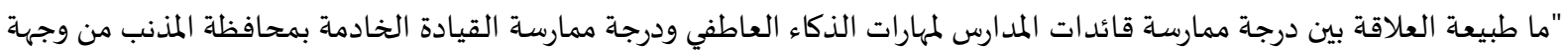

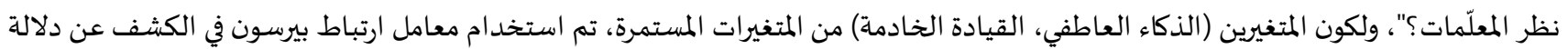

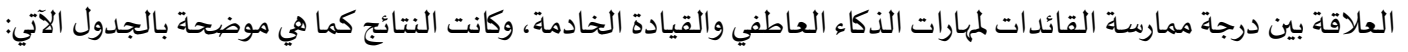

جدول (IV) ) دلالة العلاقة بين درجة ممارسة أبعاد مهارات الذكاء العاطفي ودرجة ممارسة القائدات للقيادة الخادمة من وجهة نظر المعلّمات بمحافظة المذنب.

\begin{tabular}{|c|c|c|c|c|c|c|}
\hline الدرجة الكلية & المهارات الاجتماعية & التعاطف & التحفيز والدافعية & إدارة الانفعالات & الوعي بالذات & الذكاء العاطفي \\
\hline .,人70** &.,$\lambda \vee r * *$ & , ᄉ ro** & .,^.|** &.,$\vee 乏 \wedge^{* *}$ & . & القيادة الخادمة. \\
\hline
\end{tabular}

$\boldsymbol{\alpha}=$. . دالة إحصائيًا عند مستوى دلالة

يتضح من الجدول السابق أنه: توجد علاقة ارتباطية موجبة دالة إحصائيًا عند مستوى ا..,. بين أبعاد الذكاء العاطفي (الوعي بالذات، إدارة

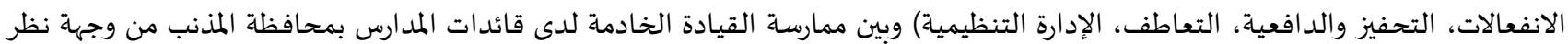
المُعلّمات.

وهذه النتيجة تشير إلى أن حجم تأثير (الدلالة العلمية) بين ممارسة كلٍّ من الدرجة الكلية لمستوى الذكاء العاطفي وأبعاد القيادة الخادمة كبيرة، كما أن

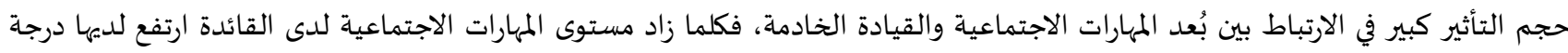

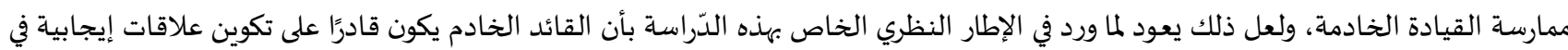

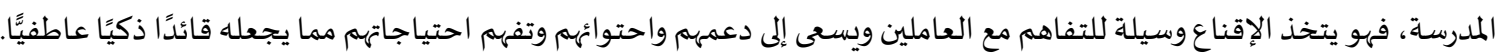

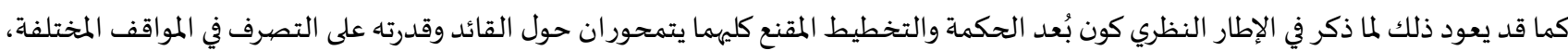

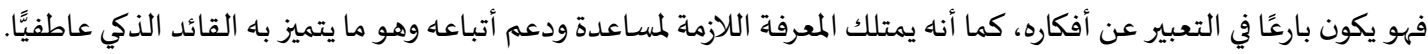
وتتفق نتائج الدّراسة في وجود علاقة دالة إحصائَّا بين مستوى الذكاء العاطفي ودرجة ممارسة القائدات للقيادة الخادمة مع دراسة (Waddell,2009) ودراسـة (Werner,2013) ودراسة (McCannon,2015) ودراسة (Gregory,2016). التوصيات:

في ضوء ما تم استخلاصها من الإطار النظري وما أسفرت عنه نتائج الدراسة الميدانية فإن الدراسة توصى بما يلى: ا. كشفت النتائج عن ذكاء عاطفي مرتفع لدى قائدات المدارس بمحافظة المذنب، مما يستدعي رعايته وتنميته عن طريق البرامج التوعوية والتدريبية

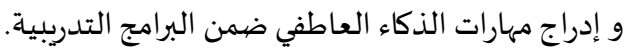
r. مراعاة توافر مهارات الذكاء العاطفي للقادة كأحد المتطلبات الضيرورية لشغل الوظائف القيادية وإدراجها ضمن استمارة تقويم الأداء الوظيفي للقيادات التربوية. r. الاهتمام بشروط تعيين القيادات التربوية وضرورة اجتياز المرشح لاختبارات مهارات الذكاء العاطفي كشرط أساسي لشغل الوظيفة. ع. عقد محاضرات ودورات تدربية للقائدات حول نمط القيادة الخادمة وكيفية توظيفه مدرسيًّا.

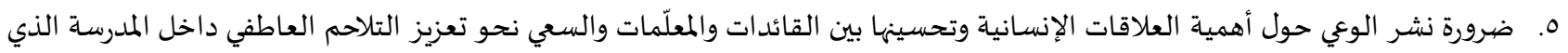
ظهر متحقق بدرجة متوسطة، وبيان دوره في نجاح الأفراد مهنيًّا.

الدراسـات المقترحة: ا. القيام بالمزيد من الدراسات حول واقع ممارسـة القائدات للقيادة الخادمة، وعلاقتها ببعض المتغيرات مثل الرضا الوظيفي والالتزام التنظيمي وسلوك المواطنة التنظيمي. r. إجراء المزيد من الدراسـات والمتعلقة بذكاء القائدة العاطفي، وعلاقته بمتغيرات أخرى كالأداء الوظيفي والقيادة التحويلية والقيادة التشاركية. 
r. إجراء دراسات أخرى مماثلة لهذه الدّراسـة، في مناطق أخرى لمعرفة العلاقة بين الذكاء العاطفي والقيادة الخادمة، ومقارنة نتائجها مع نتائج هذه الدّراسـة.

المراجع:

أولاً: المراجع العربية:

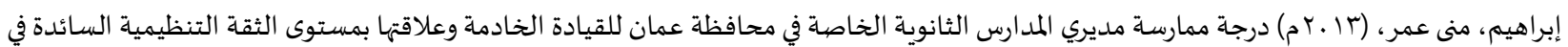

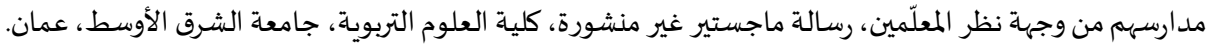

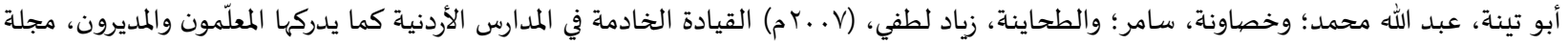

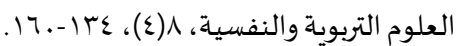

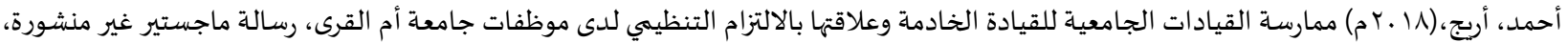
كلية التربية-جامعة أم القرى، مكة المكرمة.

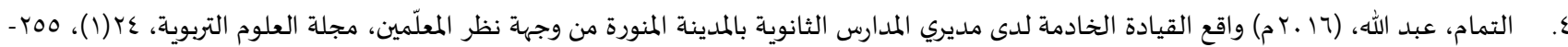
0. جامع، إبراهيم، (.1 ـ م) الذكاء الانفعالي وعلاقته بفعالية القيادة، رسالة ماجستير غير منشورة، كلية العلوم الإنسانية والعلوم الاجتماعية، جامعة منتوري قسنطينة، الجزائر.

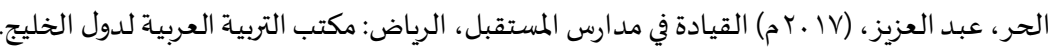

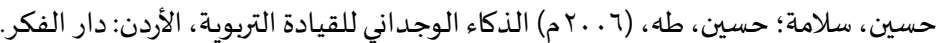

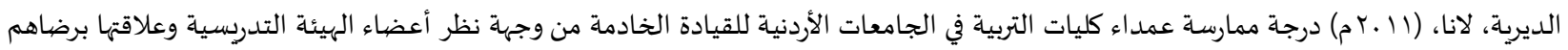
الوظيفي، رسالة ماجستير غير منشورة، الجامعة الهاشمية، الأردن.

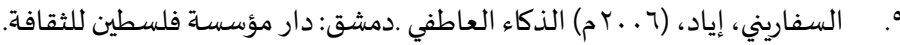

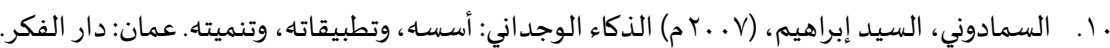

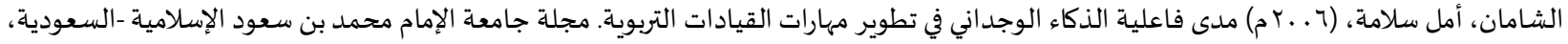
العدد 00، . . الع V-

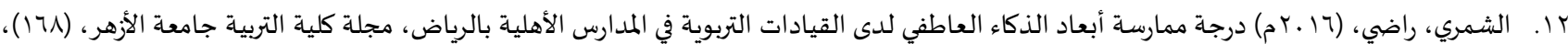
IV 1 -

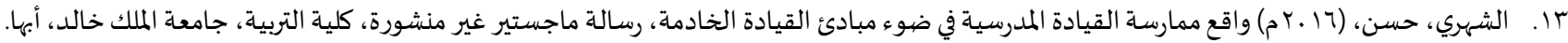

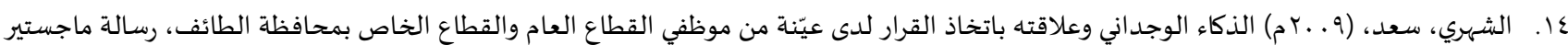

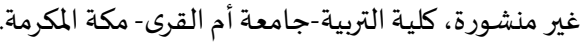

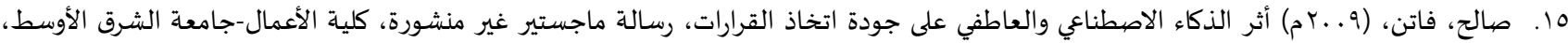
الأردن. صلاح الدين، نسرين، (17 الـ م) القيادة الخادمة لمديري المدارس والرضا الوظيفي للمعلمين في مصر: نموذج بنائي مقترح، مجلة كلية التربية بجامعة عين

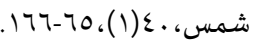

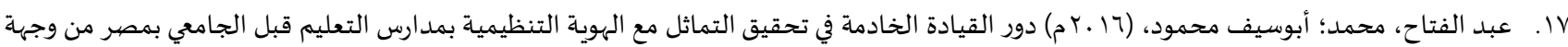

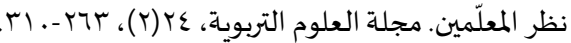

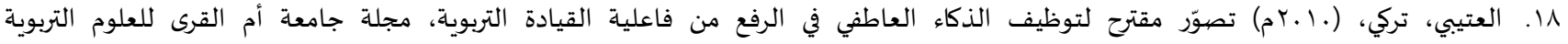

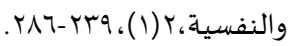

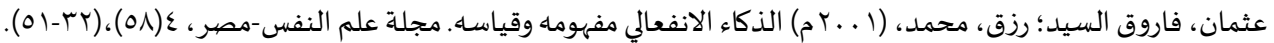

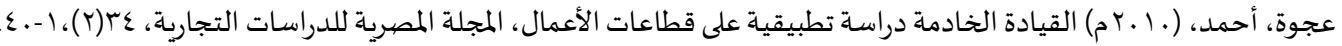

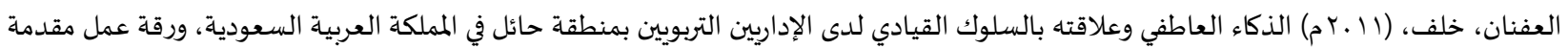
إلى المؤتمر العلهي العربي الثامن لرعاية الموهوبين والمتفوقين، الموهبة والإبداع منعطفات مهمة في حياة الشعوب، المجلد الأول، الأردن: المجلس العربي للموهوبين والمتفوقين.

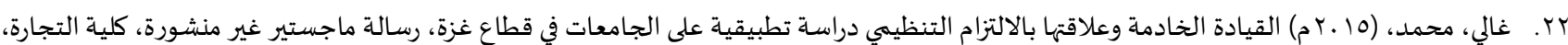
الجامعة الإسلامية، غزة.

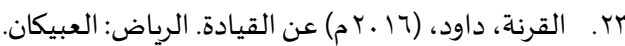

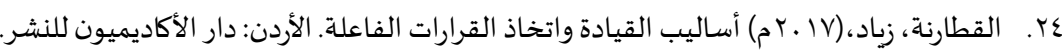


Or. القيرواني، الحسن، (19191 م) العمدة في محاسن الشعر وآدابه ونقده، بيروت: دار الجيل.

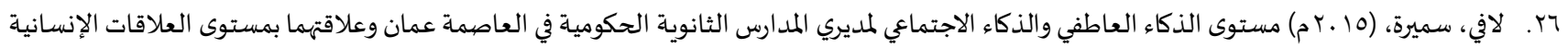

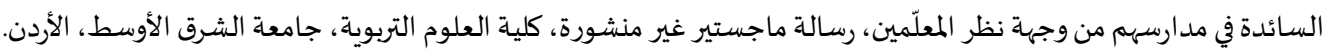

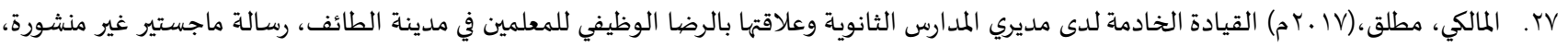
كلية التربية، جامعة أم القرى، السعودية.

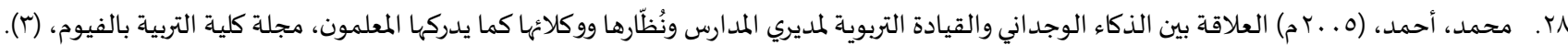

9. مصطفى، إيمان،(10 . Yم) أثر خصائص القيادة الخادمة على جودة الحياة الوظيفية، دراسة مقارنة على قطاع البنوك، المجلة العلمية للاقتصاد والتجارة، $.1 \varepsilon r-11 r .(1)$

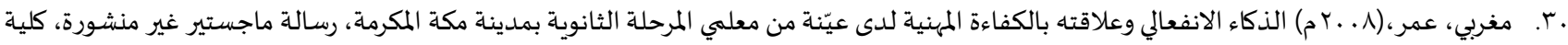
التربية، جامعة أم القرى، مكة المكرمة.

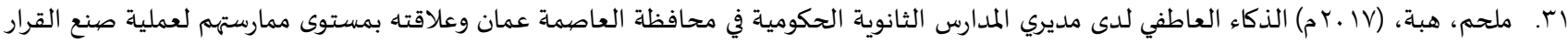

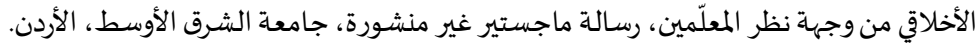

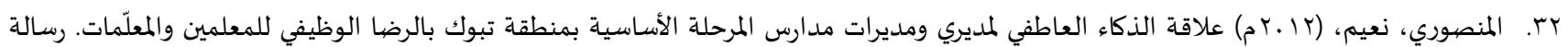
ماجستير غير منشورة، جامعة مؤته، الكرك.

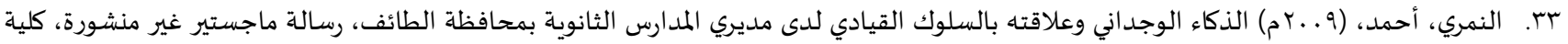

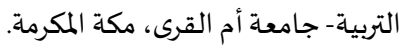

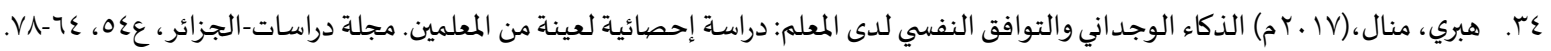
ثانياً: المراجع الأجنبية:

[1] Barbuto. J, \& Gifford, G., Examining gender differences of servant leadership: An analysis of the agentic and communal properties of the Servant Leadership Questionnaire, Journal of Leadership Education, 9(2) (2010), 4-21, https://doi.org/10.12806/v9/i2/rf1

[2] Barbuto. J., \& Wheeler. D., Scale Development and Construct Clarification of Servant Leadership, Group \& Organization Management. 31(1)(2006), 300-326, https://doi.org/10.1177/1059601106287091

[3] Bar-On,R., The Bar-On model of emotional-social intelligence (ESI), Psicothema, 18(2006), 13-25

[4] Coetzee. C., \& Schaap. P., The relationship between leadership behavior outcomes of leadership and emotional intelligence, Journal of Industrial Psychology, 31(3)(2005), 31-38, https://doi.org/10.4102/sajip.v31i3.207

[5] Goleman. D., Emotional intelligence What it can matter than(IQ), New York: Bantam, (1995)

[6] Goleman. D., Emotional intelligence. New York: Bantam, (2012)

[7] Greenleaf. R., Servant leadership: A journey into the nature of legitimate power and greatness, New York: Paulist Press, (2002)

[8] Gregory. C., Relationship between Emotional Intelligence and Servant Leadership in Banking, Unpublished PhD Thesis, Walden University, Minneapolis, (2016)

[9] Kerr. R., Garvin. J., Heaton. N. \& Boyle. E., Emotional intelligence and leadership effectiveness, Leadership \& Organization Development Journal, 27(4)(2005), 265-279, https://doi.org/10.1108/01437730610666028

[10] Krekeler. L., The Relationship between Servant Leadership Behavior and Individual Personality Style in New York Annual Conference United Methodist Pastors Unpublished master theses, Seton Hall University, New Jersey, (2010)

[11]Laub. J., A Brief Synopsis Assessing the servant organization: development of the servant organizational leadership assessment (SOLA) instrument, Unpublished PhD Thesis, Florida Atlantic University, Florida, (1999) 
[12] Mc Cannon. J., The relationship between emotional intelligence and servant leadership among public school Principals and assistant principals, Unpublished PhD Thesis, Florida Atlantic University, Florida,( 2015)

[13] Moor. B., Emotional intelligence for school administers priority for school reform, American Secondary Education .37(3)(2009), 20-28.

[14] Page. D. \& Wong. P. T., A conceptual framework for measuring servant- leadership, in The human factor in shaping the course of history and development ,Lanham: University Press of America, (2000)

[15] Patterson. K., Servant leadership: A theoretical model, Paper presented at the meeting of the Servant Leadership Roundtable, Virginia Beach, Virginia, (2003)

[16] Phipps. K., Servant leadership and constructive development theory: How servant leaders make meaning of service, Journal of Leadership Education 9(2)(2010), 151-171, https://doi.org/10.12806/v9/i2/tf1

[17] Salovey. P., \& Mayer. J., Emotional intelligence, Imagination Cognition and Personality, 9(3)(1990), 85-211.

[18] Spears. L. C., Character and servant leadership: Ten characteristics of effective, caring leaders. The Journal of Virtues \& Leadership, 1(1)(2010), 25-30.

[19] Waddell. J., Exploratory Study of the Relationship between Servant Leadership Attribution and the Leader's Emotional Intelligence, Unpublished Ph.D Thesis, Regent University, Virginia, (2009)

[20] Werner. K., An Examination of the Relationship between Emotional Intelligence and Servant Leadership Practices of Elementary Public School Principals in Washington State, Unpublished Ph.D. Thesis, Grand Canyon University, Arizona, (2013)

$$
\text { ثالثاً: المراجع الإلكترونيّة: }
$$

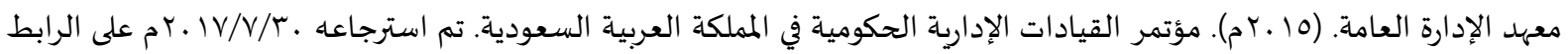
https://ipa.edu.sa/Arabic/Media/EventsConferences/Pages/Event26.aspx 


\title{
Emotional Intelligence and its Relation to the Leadership of the School Leaders in the Al-Mithnab Governorate from the Perspective of Teachers
}

\author{
Ali Saleh Alshaya \\ Professor of Educational Administration- Faculty of Education- Qassim University \\ ashyea@gmail.com
}

\section{Awatif Batah Al - Mutairi}

Master of Educational Administration- Faculty of Education- Qassim University

Mesh1434@windowslive.com

\begin{abstract}
The study aims to identify the relationship between the extent to which school female leaders have exercised emotional intelligence skills and the extent of which servant leadership was exercised from the point of view of female teachers in Al-Mithnab Governorate; if there is a statistically significant correlational relationship between the emotional intelligence and the servant leadership, for female teachers in Al-Mithnab Governorate. The study used the descriptive correlational method, and it used the questionnaire in information collection. The sample of the study was randomly selected, in terms of (264) teachers. The most important results of the study include the degree of practice of the female leaders of the schools of emotional intelligence skills was very high. There is a positive relationship between the emotional intelligence and the servant leadership of female teachers in Al-Mithnab Governorate from the point of view of female teachers. The study recommended that attention be paid to emotional intelligence, and holding lectures and training courses for female leaders on the servant leadership, as well as not forgetting the importance of human relations, and improving them between female leaders and female teachers.
\end{abstract}

Keywords: Emotional Intelligence, Servant Leadership, Al-Mithnab Governorate.

\section{References:}

[1] 'bd Ạlftạh. Mḥmd \& Ạ̉bwsyf Mḥmwd, Dwr Ạlqyạdh Ạlkḥạdmh Fy Tḥqyq Ạltmạtḥl M' Ạlhwyh Ạltnzymyh Bmdạrs Ạlt' lym Qbl Ạljạm y Bmșr Mn Wjhë Nẓr Ạlm Ĩmyn. Mjlẗ Ạl'lwm Ạltrbwyh, 24(2) (2016), 263-310.

[2] 'jwh. Ạhmd, Ạlqyạdh Ạlkḥạdmh Drạsï Tṭbyqyh 'la Qța 'ạt Ạlạ̉ mạl, Ạlmjlh Ạlmṣryh Lldrạsạt Ạltjạryh, 34(2)(2010),1-40.

[3] 'tḥmạn. Fạrwq Ạlsyd \& Rzq. Mḥmd, Ạldhַkạ’ Ạlạnf'ạly Mfhwmh Wqyạsh. Mjlï 'lm Ạlnfs-Mṣr, 4(58) (2001),(32-51).

[1] Ábrạhym. Mna 'mr, Drjë Mmạrsï Mdyry Ạlmdạrs Ạlthạnwyh Ạlkḥạṣh Fy Mḥạfụt 'mạn Llqyạdh Ạ̉lkhạadmh W'lạqthạ Bmstwy Ạlthquh Ạltnzymyh Ạlsạydh Fy Mdạrshm Mn Wjhë Nẓr Ạlm İ̃myn, Rsạlẗ Mạjstyr Ghyr Mnshwwrh, Klyêt Ạl' lwm Ạltrbwyh, Jạm ‘̆ Ạlshrq Ạlạ̉wsṭ, 'mạn, (2013)

[4] Ạ̉bw Tynh. 'bd Ạllh Mḥmd , Kḥṣạnh. Sạmr \& Ạltḥạnnh. Zyạd Lṭfy, Ạlqyạdh Ạlkḥạdmh Fy Ạlmdạrs Ạlạ̉rdnyh Kmạ Ydrkhạ Ạlm Ĩmwn Wạlmdyrwn, Mjlt Ạl'lwm Ạltrbwyh Wạlnfsyh, 8(4)(2007), 134-160.

[5] Ạ̉hmmd. Ạ̉ryj, Mmạrsẗ Ạlqyạdạt Ạljạm yh Llqyạdh Ạlkhạdmh W'lạqthạ Bạlạltzạm Ạltnzymy Ldy Mwẓfạt

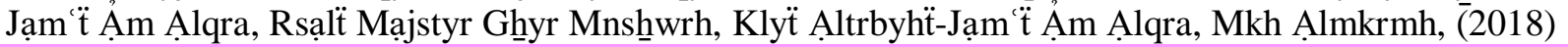




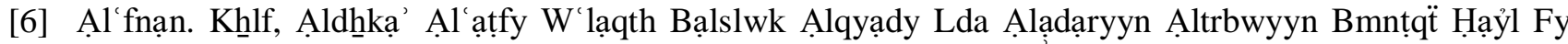
Ạlmmlkh Ạl'rbyh Ạls'wdyh, Wrq̈̈ 'ml Mqdmh ÁLa Ạlmwitmr Ạl'lmy Ạl'rby Ạlthạmn Lr'aÿ̈

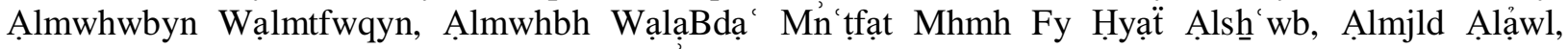
Ạlạ̉rdn: Ạlmjls Ạl'rby Llmwhwbyn Wạlmtfwqyn, (2011)

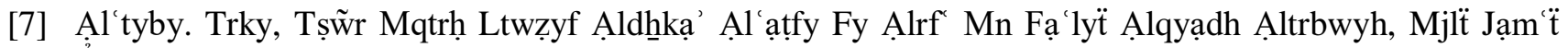
Ạm Ạlqra Ll'lwm Ạltrbwyh Wạlnfsyh,2(1)(2010),239-286.

[8] Ạldyryh. Lạnạ, Drjë Mmạrsẗ 'mdạ' Klyạt Ạltrbyh Fy Ạljạm ạt Ạlạ̉rdnyh Llqyạdh Ạlkhạdmh Mn Wjhë Nzrr Ạ̉ ḍạ' Ạlhyỷh Ạltdrysyh W'lạqthạ Brḍạhm Ạlwẓyfy, Rsạlẗ Mạjstyr Ghyr Mnshowrh, Ạljạm h Ạlhạshnmyh, Ạlạ̉rdn, (2011)

[9] Ạlḥr. 'bd Ạl'zyz, Ạlqyạdh Fy Mdạrs Ạlmstqbl, Ạlryạ̣: Mktb Ạltrbyh Ạl'rbyh Ldwl Ạlkḥlyj, (2017)

[10] Ạlmạlky. Mṭlq, Ạlqyạdh Ạlkhạdmh Lda Mdyry Ạlmdạrs Ạltḥạnwyh W'lạqthạ Bạlrḍạ Ạlwzyfy

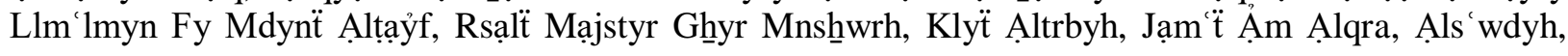
(2017)

[11] Ạlmnșwry. N'ym, 'lạqü Ạldḥkạ’ Ạl'ạtfy Lmdyry Wmdyrạt Mdạrs Ạlmrḥlh Ạlạ̉sạsyh Bmnțqï Tbwk Bạlrḍạ Ạlwzyfy Llm lmyn Wạlm Îmạt. Rsạlt Mạjstyr Ghyr Mnshwrho, Jạm ‘̈ Mw̉th, Ạlkrk, (2012)

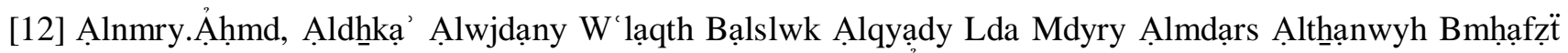
Ạltạỷf, Rsạlẗ Mạjstyr Ghyr Mnshwwrh, Klÿ̈ Ạltrbyh- Jạm ‘̈̈ Ạm Ạlqra, Mkh Ạlmkrmh, (2009)

[13] Ạlqrnh. Dạwd, 'n Ạlqyạdh. Ạlryạd: Ạl'bykạn, (2016)

[14] Ạlqțạrnh. Zyạd, Ạ̉sạlyb Ạlqyạdh Wạtkḥạdhِ Ạlqrạrạt Ạlfạ 'lh. Ạlạ̉rdn: Dạr Ạlạ̉kạdymywn Llnshnr, (2017)

[15] Ạlqyrwạny. Ạlḥsn, Ạl’mdh Fy Mhạsn Ạlsḥłr Wậdạbh Wnqdh, Byrwt: Dạr Ạljyl, (1981)

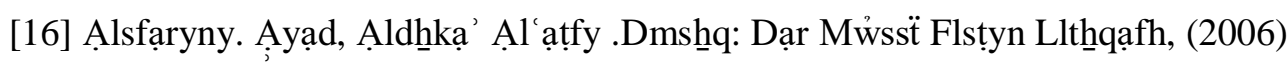

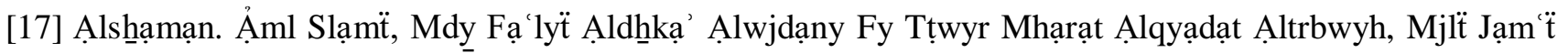
ẠlạjMạm Mḥmd Bn S'wd Ậạ̦Slạmyh -Ạls wdyh, (55)(2006), 470-517.

[18] Ạlshhhry. Ḥsn, Wạq ' Mmạrsẗ Ạlqyạdh Ạlmdrsyh Fy Ḍw’ Mbạdỷ Ạlqyạdh Ạlkḥạdmh, Rsạlẗ Mạjstyr Ghyr Mnshnwrh, Klÿ̈ Ạltrbyh, Jạm ‘̈ Ạlmlk Khạald, Ạ̉bhạ, (2016)

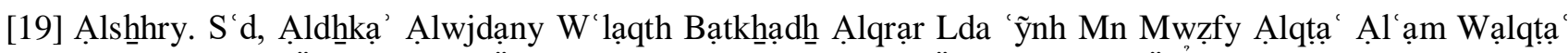

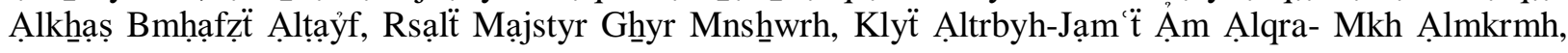
(2009)

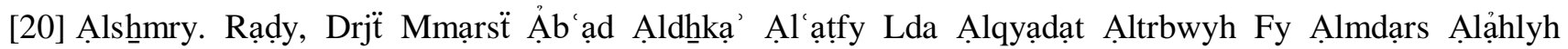
Bạlryạ̣, Mjl̈̈ Klÿ̈ Ạltrbyh Jạm‘̋̈ Ạlạ̉zhr, (168)(2016), 143-174.

[21] Ạlsmạdwny. Ạlsyd ẠBrạhym, Ạldhkạa' Ạlwjdạny: Ạ̉ssh, Wtṭbyqạth, Wtnmyth. 'mạn: Dạr Ạlfkr, (2007)

[22] Ạltmạm. 'bd Ạllh, Wạq Ạlqyạdh Ạlkhạdmh Lda Mdyry Ạlmdạrs Ạlthạanwyh Bạlmdynh Ạlmnwrh Mn Wjhẗ Nẓr Ạlm Ĩmyn, Mjlë Ạl'lwm Ạltrbwyh, 24(1)(2016), 255-309.

[23] Barbuto. J, \& Gifford, G., Examining gender differences of servant leadership: An analysis of the agentic and communal properties of the Servant Leadership Questionnaire, Journal of Leadership Education, 9(2) (2010), 4-21, https://doi.org/10.12806/v9/i2/rf1

[24] Barbuto. J., \& Wheeler. D., Scale Development and Construct Clarification of Servant Leadership, Group \& Organization Management. 31(1)(2006), 300-326, https://doi.org/10.1177/1059601106287091 
[25] Bar-On, R., The Bar-On model of emotional-social intelligence (ESI), Psicothema, 18(2006), 13-25

[26] Coetzee. C., \& Schaap. P., The relationship between leadership behavior outcomes of leadership and emotional intelligence, Journal of Industrial Psychology, 31(3)(2005), 31-38,

https://doi.org/10.4102/sajip.v31i3.207

[27] Ghạly. Mḥmd, Ạlqyạdh Ạlkhạadmh W'lạqthạ Bạlạltzạm Ạltnzymy Drạsh Tṭbyqyh 'la Ạljạm ạ̣t Fy Qțạ'

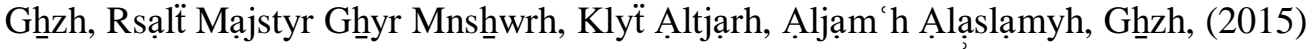

[28] Goleman. D., Emotional intelligence What it can matter than(IQ), New York: Bantam, (1995)

[29] Goleman. D., Emotional intelligence. New York: Bantam, (2012)

[30] Greenleaf. R., Servant leadership: A journey into the nature of legitimate power and greatness, New York: Paulist Press, (2002)

[31] Gregory. C., Relationship between Emotional Intelligence and Servant Leadership in Banking, Unpublished PhD Thesis, Walden University, Minneapolis, (2016)

[32] Hbry. Mnạl, Ạldḩkạ’ Ạlwjdạny Wạltwạfq Ạlnfsy Lda Ạlm 'lm: Drạsh Ặșạyyh L ynh Mn Ạlm 'lmyn. Mjlẗ Drạsạt-Ạljzậr, (54)(2017), 64-78.

[33] Ḥsyn. Slạmë; Ḥssyn, Ṭh, Ạldhַkạ’ Ạlwjdạny Llqyạdh Ạltrbwyh, Ạlạ̉rdn: Dạr Ạlfkr, (2006)

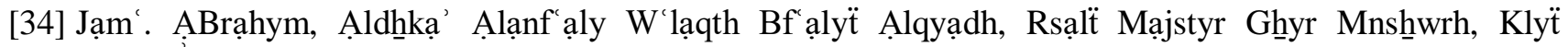
Ạl'lwm Ạlạnsạnyh Wạl' lwm Ạlạjtmạ yh, Jạm ‘̈ Mntwry Qsnțnh, Ạljzậrr, (2010)

[35] Kerr. R., Garvin. J., Heaton. N. \& Boyle. E., Emotional intelligence and leadership effectiveness, Leadership \& Organization Development Journal, 27(4)(2005), 265-279, https://doi.org/10.1108/01437730610666028

[36] Krekeler. L., The Relationship between Servant Leadership Behavior and Individual Personality Style in New York Annual Conference United Methodist Pastors Unpublished master theses, Seton Hall University, New Jersey, (2010)

[37] Lạfy. Smyrh, Mstwy Ạldhַkạ’ Ạl'ạtfy Wạldḥkạ' Ạlạjtmạ y Lmdyry Ạlmdạrs Ạlthạnwyh Ạlhkwmyh Fy Al 'ạsmh 'mạn W' lạqthmạ Bmstwy Al lạqạt Ạlạnsạnyh Ạlsạydn Fy Mdạrshm Mn Wjhë Nẓr Ạlm Î̃myn,

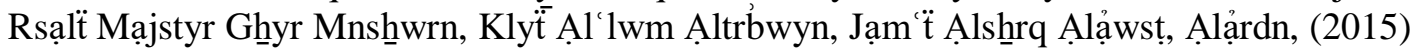

[38] Laub. J., A Brief Synopsis Assessing the servant organization: development of the servant organizational leadership assessment (SOLA) instrument, Unpublished PhD Thesis, Florida Atlantic University, Florida, (1999)

[39] Mc Cannon. J., The relationship between emotional intelligence and servant leadership among public school Principals and assistant principals, Unpublished $\mathrm{PhD}$ Thesis, Florida Atlantic University, Florida, (2015)

[40] Mgḥrby. 'mr, Ạldȟkạ' Ạlạnf'ạly W'lạqth Bạlkfạ'h Ạlmhnyh Lda 'ỹnh Mn M'lmy Ạlmrḥlh Ạlthạnwyh

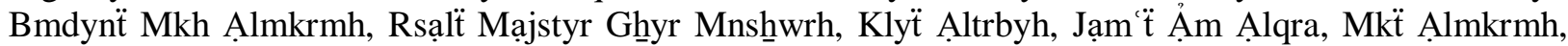
(2008)

[41] Mḥmd. Ạ̉hmo, Ạl'lạqh Byn Ạldḥkạ’ Ạlwjdạny Wạlqyạdh Ạltrbwyh Lmdyry Ạlmdạrs Wnuzạarhạ Wwklạyhhạ Kmạ Ydrkhạ Ạlm 'lmwn, Mjlë Klyẗ Ạltrbyh Bạlfywm, (3)(2005), 1-75. 


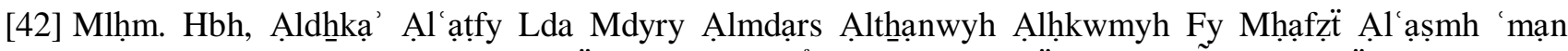
W' lạqth Bmstwy Mmạrsthm L'mlyẗ Șn' Ạlqrạr Ạlạ̉khlạqy Mn Wjhẗ Nẓr Ạlm Î̃myn, Rsạlẗ Mạjstyr Ghyr

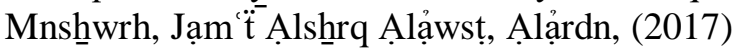

[43] Moor. B., Emotional intelligence for school administers priority for school reform, American Secondary Education .37(3)(2009), 20-28.

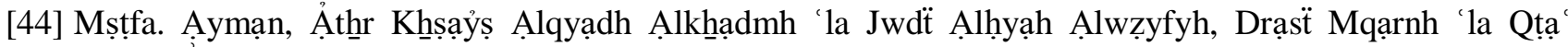
Ạlbnwk, A.lmjlh Ạl'lmyh Llạqtṣạd Wạltjạrh, (1)(2015),113-143.

[45] Page. D. \& Wong. P. T., A conceptual framework for measuring servant- leadership, in The human factor in shaping the course of history and development ,Lanham: University Press of America, (2000)

[46] Patterson. K., Servant leadership: A theoretical model, Paper presented at the meeting of the Servant Leadership Roundtable, Virginia Beach, Virginia, (2003)

[47] Phipps. K., Servant leadership and constructive development theory: How servant leaders make meaning of service, Journal of Leadership Education 9(2)(2010), 151-171, https://doi.org/10.12806/v9/i2/tf1

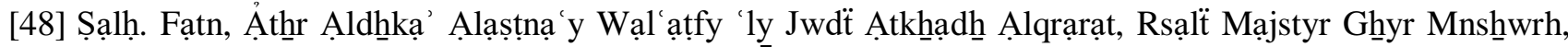

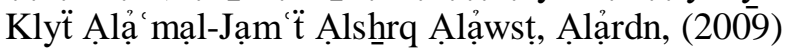

[49] Șlạh Ạldyn. Nsryn, Ạlqyạadh Ạlkḥạdmh Lmdyry Ạlmdạrs Wạlrḍạ Ạlwẓyfy Llm lmyn Fy Mṣr: Nmwdḥj

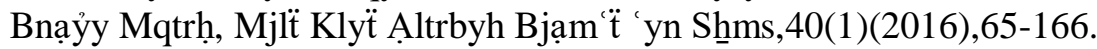

[50] Salovey. P., \& Mayer. J., Emotional intelligence, Imagination Cognition and Personality, 9(3)(1990), 85211.

[51] Spears. L. C., Character and servant leadership: Ten characteristics of effective, caring leaders. The Journal of Virtues \& Leadership, 1(1)(2010), 25-30.

[52] Waddell. J., Exploratory Study of the Relationship between Servant Leadership Attribution and the Leader's Emotional Intelligence, Unpublished PhD Thesis, Regent University, Virginia, (2009).

[53] Werner. K., An Examination of the Relationship between Emotional Intelligence and Servant Leadership Practices of Elementary Public School Principals in Washington State, Unpublished Ph.D. Thesis, Grand Canyon University, Arizona, (2013). 